\title{
Electrocatalysis of Oxygen Reduction in Polymer Electrolyte Fuel Cells: A Brief History and a Critical Examination of Present Theory and Diagnostics
}

\author{
SHIMSHON GOTTESFELD
}

Cellera Technologies, Caesarea, Israel

\subsection{INTRODUCTION}

The title that I chose for my talk in Leiden was "Electrocatalysis-a scan over 20 years + one great meeting." Although the superlative used in the name of the talk was chosen well before the meeting itself, it will be seen from this chapter that the meeting indeed provided significant further food for thought, at least in the case of this participant, regarding the fundamentals of fuel cell electrocatalysis. Of particular interest has been the dialogue between the recent advances in the theory of electrocatalysis and the corresponding experimental data collected to date, that should serve as a basis for solid mechanistic conclusions and define a road map for the future. This chapter will first describe, in line with its original assignment, key milestones in the development of electrocatalysts for low temperature fuel cells, leading next to a discussion of the state of the art in the field. Both the historical comments and, particularly, the latter part of the chapter, devoted to a critical examination of the state of the art, are focused on the oxygen reduction reaction (ORR). The ORR remains the most serious challenge to both fuel cell experimentalists and theorists, as is evident from the major contribution that the air cathode loss makes at present to the overall voltage loss of a polymer electrolyte fuel cell (PEFC), or any other low temperature fuel cell. This is despite the significant experimental and, particularly, theoretical advances in air cathode electrocatalysis in PEFCs that have been made since the year 2000.

Fuel Cell Catalysis. Edited by Marc T. M. Koper Copyright (C) 2009 John Wiley \& Sons, Inc. 
Specific aspects examined here include insights and conclusions derived from the most recently performed density functional theory (DFT) calculations, which have been based on a comprehensive model of the electrochemical interface, and the strong disagreements (which seem to defy all recent theoretical efforts) that remain regarding proper interpretation of experimental ORR results and proper identification of the ORR mechanism in a PEFC cathode employing Pt catalysts.

\subsection{KEY MILESTONES ON THE WAY TO THE PRESENT STATE OF THE ART OF FUEL CELL ELECTROCATALYSIS}

When surveying the central milestones in the development of electrocatalysis for low temperature fuel cells operating in acidic environments, the following, listed in chronological order, seem to be the most outstanding:

- Establishment of carbon-supported Pt catalysts as a means to achieve higher and more stable dispersion of the precious metal electrocatalyst on an electronically conducting support [Petrow and Allen, 1977].

- Implementation of Pt/C catalysts in PEFC technology using recast Nafion ${ }^{\circledR}$ as a proton conducting and bonding agent [Raistrick, 1986; Wilson and Gottesfeld, 1992].

- Optimization of the catalyst layer composition and thickness in PEFCs for maximum catalyst utilization in operation on air and on impure hydrogen feed streams [Wilson, 1993; Springer et al., 1993].

- Advancing from carbon-supported Pt to carbon-supported Pt alloy catalysts, to enhance the performance per milligram Pt by three- to four-fold [Mukerjee and Srinivasan, 1993; Mukerjee et al., 1995].

- Moving on from preparation of homogenous Pt alloy particles to tailoring of core-and-shell alloy particles, targeting (i) further lowering of the mass of precious metal per unit power output and (ii) further boost of catalytic activity per square centimeter of catalyst area [Zhang et al., 2004].

Two parallel efforts common to all of the above critical steps and milestones are (i) maximizing of catalyst dispersion and enhancing electrochemical utilization of the overall surface area of the catalyst incorporated in the fuel cell electrode and (ii) further fine tuning of the electronic and, consequently, surface chemistry properties of Pt catalysts by alloying, typically with electropositive metals such as $\mathrm{Co}$ or $\mathrm{Ni}$, to achieve higher activity per unit surface area of the optimized alloy catalysts. The former part of the effort led to established methods of preparation of carbon-supported Pt alloy particles in the diameter range of $2-5 \mathrm{~nm}$, i.e., of overall catalyst surface area between 600 and $1500 \mathrm{~cm}^{2} \mathrm{Pt}$ (or Pt alloy) per square centimeter of electrode crosssectional area achieved at a mass loading of only $1 \mathrm{mg} \mathrm{Pt}$ (or Pt alloy) per square centimeter of cross-sectional area. Such high "electrode surface amplification factors" are enabled by carefully selected mild reduction processes that generate, typically from 
chloroplatinic acid, a large number of nanometer-size Pt metal nuclei on the carbon support, while slowing down the rate of excessive Pt crystallite growth. Alloying of the Pt nanoparticles is typically achieved by reaction of the carbon-supported Pt crystallites with added oxide of the electropositive metal, e.g., Co or $\mathrm{Ni}$, and results in some increase in size of the catalyst particles, typically from around $2 \mathrm{~nm}$ in unalloyed form to $4-5 \mathrm{~nm}$ in the alloyed form. These high electrode surface area amplification factors, of the order of $10^{2}-10^{3}$, have clearly been key for achieving the specific activity of hydrogen/air PEFC electrodes, enabling lowering of the loading required in fuel cell stacks to only $0.2 \mathrm{~g}$ Pt catalyst per kilowatt of power generated [Gasteiger, 2005].

Particle size effect: Since the total surface area of the dispersed catalyst available at some given mass loading (in milligrams per geometric square centimeter, $\mathrm{mg} / \mathrm{cm}^{2}$ geo.), is inversely proportional to the particle diameter, further reduction of the Pt particle size to less than $2 \mathrm{~nm}$ has been pursued by several groups, with associated efforts to modify the carbon support so as to reduce inter-Pt particle distance (see Chapter 10). However, this route to further increase of the Pt catalyst surface area has encountered difficulties, interpreted by most researchers by the lower intrinsic activity obtainable per $\mathrm{cm}^{2} \mathrm{Pt}$ at such ultrasmall particle sizes. This lower catalyst surface activity reported for such small particle sizes, particularly in the oxygen reduction process, has been understood to be the result of a larger fraction of Pt atoms located in edge site, rather than in terraces of catalytically preferred Pt crystal surfaces, or in steps that could enable multisite interaction. Strong evidence for the benefit of trading off ultrahigh surface area for a "smoother" catalyst surface morphology has been provided by the unique development at 3M Company of electrocatalyst layers based on sputter coating by $\mathrm{Pt}$ of an array of micrometer-long inert dendrites that are subsequently embedded into the ionomeric membrane [Debe et al., 2003]. Activities per $\mathrm{cm}^{2} \mathrm{Pt}$ obtained with this structure of a supported catalyst are about five times higher than those recorded for $2 \mathrm{~nm}$ size Pt particles supported on carbon, fully compensating for the similar loss in Pt surface area per unit mass compared with the case of $2 \mathrm{~nm}$ supported Pt particles. It should be noted here that a dissenting opinion in this regard has been expressed through the years by Watanabe and co-workers, namely that the loss of activity with drop in Pt particle size has only to do with exacerbated, localized mass transport limitations within the structure of the catalyst layer, caused by low interparticle distance (see Chapter 10). Whereas this dissenting opinion suggests that further optimization of catalyst layer composition and structure could enable the use of Pt particles of diameters smaller than $2 \mathrm{~nm}$, i.e., enable higher surface area per unit mass of $\mathrm{Pt}$, most researchers in the field have accepted the conclusion that reducing particle size to below $2-3 \mathrm{~nm}$ does not enhance the activity per unit mass of Pt, because of intrinsic surface catalysis reasons, apparently to do with the surface atomic structure of such very small Pt particles.

Catalyst layer architecture: As a consequence of the diminishing returns from ever higher dispersion, the effort to increase the active catalyst surface area per unit mass of Pt has centered in recent years primarily on optimization of catalyst layer properties, aiming to maximize "catalyst utilization" in fuel cell electrodes based on Pt catalyst particle sizes of $2-5 \mathrm{~nm}$. High catalyst utilization is conditioned on access to the largest possible percentage of the total catalyst surface area embedded in a catalyst 


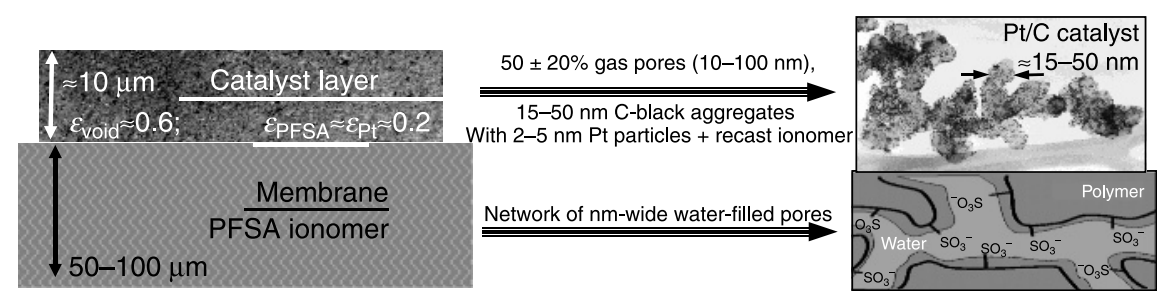

Figure 1.1 The nature of a composite, $\mathrm{Pt} / \mathrm{C} /$ recast ionomer layer with a structure that enables high electronic and gas mobilities as well as sufficient proton mobility [Gasteiger, 2005].

layer by the three participants in the electrochemical process-gaseous reactant, protons, and electrons - all at the rates called for by the demand current density. Fulfilling the latter condition requires a composite catalyst layer structure in which the electron mobility, the proton mobility, and the effective gas diffusivity across the thickness dimension of the catalyst layer are all sufficient, at the demand current, to access the maximum fraction of the catalyst particles dispersed uniformly in the $(5-20 \mu \mathrm{m}$ thick) catalyst layer. The type of structure satisfying high catalyst utilization in catalyst layers of PEFCs is shown in Fig. 1.1.

The figure shows catalyst layer porosity at both micrometer and nanometer scales. The larger pores form as a result of the highly structured nature of the carbon support, that prevents closer packing of the submicrometer carbon particles, facilitating gas transport through the catalyst layer. It is easy to see that the carbon structure obtained will support electron percolation with the roughly $30 \%$ volume fraction occupied by the carbon particles. However, achieving higher proton mobility is usually a bigger challenge. As can be seen from Fig. 1.1, the proton-conducting component of the catalyst layer, typically applied as a solution of the ionomer which recasts around carbon particles [Gasteiger, 2005], needs to reach a volume fraction that would satisfy the ionic conductivity demand, but, at the same time, would leave the network of micropores sufficiently open to gas transport. The specific conductivity of the ionomer is several orders of magnitude smaller than that of the carbon and, as a result, the performance of the membrane/electrode assembly will typically be limited by the effective protonic conductivity within the catalyst layer, thereby diminishing the effective overpotential at catalyst particles located away from the surface of the ionomeric membrane [Springer et al., 1993]. A reverse situation, in which catalyst particles away from the gas diffusion layer are the least well utilized, will apply when the gas permeability through the catalyst layer becomes the main transport limiting factor.

The most recent improvements in Pt catalyst utilization $U$ by optimization of catalyst layer composition and structure have led to catalyst utilizations as high as $80 \%$, or more, determined as the ratio between measured ORR current per geometric square centimeter of electrode area and the current expected from the total measured $\mathrm{Pt}$ surface area per geometric square centimeter of the electrode, i.e.,

$$
U=\frac{J_{\mathrm{ORR}}(E, T)}{A_{\mathrm{Pt}}^{*} J_{\mathrm{ORR}}^{*}(E, T)}
$$


where $J_{\mathrm{ORR}}^{*}(E, T)$ is the ORR current per $\mathrm{cm}^{2} \mathrm{Pt}$ at cathode potential $E$, determined by an independent measurement at a Pt electrode of known surface area (and well-defined mass transport characteristics) and $A_{\mathrm{Pt}}^{*}$ is the number of $\mathrm{cm}^{2} \mathrm{Pt}$ per geometric $\mathrm{cm}^{2}$ of the fuel cell cathode, determined from the hydrogen adsorption charge or the $\mathrm{CO}$ desorption charge as measured by voltammetry. The ability to achieve catalyst utilizations as high as $80 \%$ in PEFC cathodes (even more easily achieved on the anode side) by optimizing the composition and structure of the catalyst layer, means that this degree of freedom in enhancing further the net electrocatalytic activity has been exhausted to a significant degree. This said, some remaining opportunity for further enhancing the rate of the cathode process through better catalyst utilization has been argued very recently, based on (i) higher utilizations determined from Reaction (1.1) demonstrated for types of carbon support material of higher surface area [Toyota R\&D Center, 2007] and (ii) the argument that $A_{\mathrm{Pt}}^{*}$, the "electrochemically active" surface area determined by voltammetry, may not include the area of Pt catalyst particles dislodged from the carbon support during catalyst layer preparation. This argument implies that the performance of the air cathode in the fuel cell can likely be further improved, at some given temperature, by a factor of about 2 with further perfection of the carbon/PFSA ionomer composite catalyst layer composition and mode of fabrication. Such a performance gain is not insignificant, but, at the same time, leaves ample room for further, larger reductions of air electrode losses.

Pt demand per $k W$ versus PEFC performance and cost targets: The presently achieved PEFC air cathode (initial) performance with $\mathrm{Pt} / \mathrm{C}$ catalysts is basically defined, as explained above, by a Pt cathode catalyst surface area of 600-1500 $\mathrm{cm}^{2} / \mathrm{mg} \mathrm{Pt}$ and by the intrinsic ORR catalytic activity at the (bulk) Pt/ionomer interface at some given temperature and ionomer hydration level, $J_{\mathrm{ORR}}\left(V_{\text {cath }}, T_{\text {cell }}, \mathrm{RH}\right) /$ $\mathrm{cm}^{2} \mathrm{Pt}$. At the lower end of catalyst dispersion specified above, the intrinsic ORR activity per $\mathrm{cm}^{2} \mathrm{Pt}$ is maintained similar to that of the bulk metal. Reading the quality of catalytic activity obtained state-of-the-art dispersed $\mathrm{Pt} / \mathrm{C}$ catalyst is done in somewhat different ways from a PEFC technology perspective and from an ORR electrocatalysis science perspective. From a technology implementation perspective, the question is: "How close is this PEFC technology based on carbon-supported Pt catalyst to market-entry targets of PEFC stack performance and cost?" From the perspective of electrocatalysis fundamentals, the question is: "With the cathode remaining the largest source of PEFC voltage loss, by far, what can be further done to improve performance by moving away from the Pt/C ORR catalyst to another catalyst of higher intrinsic electrocatalytic activity?" Starting from the technology perspective, in a PEFC operating at $80{ }^{\circ} \mathrm{C}$, the electrocatalytic activity derived from state-of-the-art catalyst dispersion and catalyst utilization described above, the PEFC cathode activity measured at $V_{\text {cath }}=0.90 \mathrm{~V}$ is $0.11 \mathrm{~A}$ per $\mathrm{mg} \mathrm{Pt}$ and increases 10 -fold at $V_{\text {cath }}=$ $0.84 \mathrm{~V}$ [Gasteiger, 2005]. This would translate to nearly $1 \mathrm{~W}$ per $\mathrm{mg} \mathrm{Pt}$ at $V_{\text {cath }}=$ $0.84 \mathrm{~V}$, enabling one to achieve with $1 \mathrm{mg}$ Pt per square centimeter of electrode geometric area an areal power density of $1 \mathrm{~W} / \mathrm{cm}^{2}$, translating to a bulk power density of the cell of around $1 \mathrm{~W} / \mathrm{cm}^{3}$, i.e., a respectable power density of $1 \mathrm{~kW}$ per liter of the stack at a cell voltage as high as $0.8 \mathrm{~V}$. However, the Pt catalyst mass required for 
operation at such level of power density and at a conversion efficiency higher than $60 \%$, i.e., $1 \mathrm{mg} \mathrm{Pt} / \mathrm{W}$, or $1 \mathrm{~g} \mathrm{Pt} / \mathrm{kW}$, translates at the present market price of $\mathrm{Pt}$ metal to $\$ 50 / \mathrm{kW}$. Such a cost of the catalyst component of a power source, may possibly enable technology implementation for some stationary or portable power applications, where the cost of the relevant incumbent power technology is in the hundreds and thousands of dollars per kilowatt, respectively. The same catalyst cost is prohibitive, however, in transportation applications, where the overall cost per kilowatt of the incumbent technology, i.e., the internal combustion engine, is similar to, or lower than the cost of just the Pt catalyst required per kilowatt of fuel cell stack at the present state of PEFC electrode technology and the present market price of Pt. Consequently, the greatest drive during the last few years to lower the catalyst loading in a PEFC stack to $0.1-0.2 \mathrm{~g} / \mathrm{kW}$, i.e., $5-10$ times lower than is possible with $\mathrm{Pt} / \mathrm{C}$ catalysts, has come from programs and teams pursuing transportation applications of PEFCs.

Pt alloy catalysts: While driven technologically by the demanding cap on Pt usage per unit power generated, the development of Pt alloy catalysts of higher ORR activity has been driven scientifically by the pursuit of the fundamental physical parameter(s) that determine the electrocatalytic activity of metals and metal alloys in the ORR. As this aspect of electrocatalysis research is covered extensively in this book, mention will be made here only of recent central achievements in (i) the actual introduction of $\mathrm{Pt}$ alloy/C catalysts into PEFC cathodes, demonstrating for such PEFCs an advantage in cell power per $\mathrm{mg} \mathrm{Pt}$ of about fourfold compared with the non-alloyed $\mathrm{Pt} / \mathrm{C}$ catalyst, and (ii) the coupled theoretical and experimental research efforts since the year 2000, leading to an understanding of the origin of the higher ORR activity observed following proper alloying of $\mathrm{Pt}$ and, indeed, to forecasts on possible further improvements in ORR catalysis.

The specific Pt alloy that has been introduced more than any other as a carbonsupported cathode catalyst in PEFCs has been PtCo. It belongs to the first group of catalysts considered as possible ORR activity enhancers in PEFCs, a group that also included $\mathrm{Pt}_{3} \mathrm{Cr}$ and $\mathrm{Pt}_{3} \mathrm{Ni}$ [Mukerjee and Srinivasan, 1993; Mukerjee et al., 1995]. In fact, this choice was inspired by the similar ORR activity enhancement observed for this group of alloys in earlier development of cathode catalysts for the phosphoric acid fuel cell (PAFC). Incorporation of these alloys, starting more than 20 years ago, in cathodes of commercial PAFC power units fabricated by UTC (Connecticut, US), was based on the superior activity of the alloy per unit mass of Pt compared with the unalloyed $\mathrm{Pt} / \mathrm{C}$ catalyst. When the first measurements of the changes in electronic properties of $\mathrm{Pt}$ on alloying with $\mathrm{Co}, \mathrm{Ni}$, or $\mathrm{Cr}$ were reported [Mukerjee and Srinivasan, 1993; Mukerjee et al., 1995], it was still not clear why an increase should be observed in Pt $d$-band vacancy following alloying and why that would necessarily lead to higher ORR activity compared with unalloyed Pt. What helped here was electrochemical surface characterization by cyclic voltammetry, which revealed a shift of the onset of $\mathrm{OH}$ or $\mathrm{O}$ electrosorption to higher anodic potential as a result of alloying, suggesting a lowered tendency of the metal alloy surface to chemisorb $\mathrm{O}$ or $\mathrm{OH}$ by water discharge, as compared with unalloyed Pt. Such lowered affinity for oxygen would be difficult to rationalize for a surface containing, e.g., Co atoms in addition to Pt atoms; however, experimental evidence then appeared of spontaneous formation on such PtCo alloy particles of a single-atom-thick shell of 
$\mathrm{Pt}$ atoms around a PtCo alloy core. With such a core-and-shell structure, the lowered drive of the Pt shell atoms to bond to surface oxygen atoms could be now understood as the result of the involvement of $d$-electrons of shell Pt atoms in bonding to Co atoms in the adjacent atomic layer underneath the shell, resulting in lower availability of $d$ electrons in the surface $\mathrm{Pt}$ atoms for formation of a surface bond to an $\mathrm{OH}$ group or an $\mathrm{O}$ atom. This observed correlation between higher ORR activity and lowered surface affinity to chemisorbed $\mathrm{O}$ or $\mathrm{OH}$ revealed that the surface affinity to oxygen of unalloyed Pt surfaces is apparently somewhat too high to achieve optimized cathode catalytic activity, and, consequently, a slight lowering of the catalyst surface affinity to oxygen through alloying enhances the rate of the ORR.

Interpretation of this observed correlation between a lowered affinity of the metal surface to oxygen and a higher rate of ORR measured at a Pt shell over a Pt-alloy core has also been at the center of recent theoretical work, based primarily on DFT calculations of electronic properties and surface bond strengths for a variety of expected ORR intermediates at metal and metal alloy catalysts. The second part of this chapter contains a discussion of these valuable contributions and of outstanding issues in tying together this recent theoretical work and ORR experimental data.

Core-and-shell-type electrocatalyst particles have most recently defined the frontier in ORR electrocatalysis research. Not only can this structure enable fine tuning of the electronic properties of surface $\mathrm{Pt}$ atoms, it could also allow placing of all the Pt atoms only on the outer surface of the catalyst particle, i.e., where the catalytic process takes place, using non-precious metal atoms in the particle core. By having all $\mathrm{Pt}$ atoms located on the outer surface (shell) of a core-and-shell catalyst particle, the mass of Pt required to generate some given Pt catalyst surface area would drop by a factor of 5-10 compared with catalyst particles built exclusively of Pt atoms. Consequently, the cost of the catalyst per unit power generated could drop by a similar factor of 5-10 if the particle core were made of non-precious metal(s). Several recent demonstrations of this approach have included a Pt shell over a Ru core as a CO-tolerant anode catalyst and a Pt shell on a Pd core for the ORR process, both made by Adzic et al. [Zhang et al., 2004 and references therein]. The most recent work in this area is covered in Chapters 8 and 9.

A remaining great challenge in the introduction of such atomic-level tailored nanoparticles of electrocatalysts is maintenance of the stability of the preferred surface atomic structure under fuel cell operation conditions. Encouraging results in this regard for Pt shell/Ru core anode catalysts tested for 1000 hours were facilitated by the reducing environment in the anode. The most researched cathode alloy catalyst, carbon-supported $\mathrm{Pt}$ shell $/ \mathrm{Pt}_{3} \mathrm{Co}$ core, was first reported to be even more stable than unalloyed carbon-supported $\mathrm{Pt}$, but more recently a performance decay pattern reported by Johnson Matthey [Thompset, 2007] showed accelerated decay following the first 1000 hours, which was explained by loss of near-surface Co atoms, leaving behind a faulty structure of surface Pt atoms. Basically, under fuel cell cathode operating conditions, it will be highly nontrivial to achieve the operational stability required with shell-and-core catalyst particles employing highly electropositive atoms such as $\mathrm{Co}, \mathrm{Fe}$, or $\mathrm{Ni}$, because of the strong tendency of such atoms to leave the metal alloy crystal and form metal ions. 


\subsection{ELECTROCATALYSIS OF OXYGEN REDUCTION IN THE FUEL CELL CATHODE: NEW INSIGHTS AND NEW QUESTIONS}

Significant advances have been made since the year 2000 in the theoretical analysis of the ORR at Pt metal electrocatalysts. These recent theoretical advances have been made using DFT calculations considering model systems of good resemblance to the actual electrochemical interface. Models of the interface used in such recent calculations include a significant ensemble of metal atoms (Fig. 1.2) [Nørskov et al., 2004] (rather than a single metal atom or a pair of metal atoms as was done in pioneering contributions made somewhat earlier [Anderson et al., 2000]), as well as the aqueous molecular environment adjacent to the metal catalyst surface. Last, but not least, the effects of variations in the electrode-electrolyte potential difference on interfacial thermodynamics and dynamics have also been included in these models [Nørskov et al., 2004; Panchenko et al., 2004; Desai and Neurock, 2003].

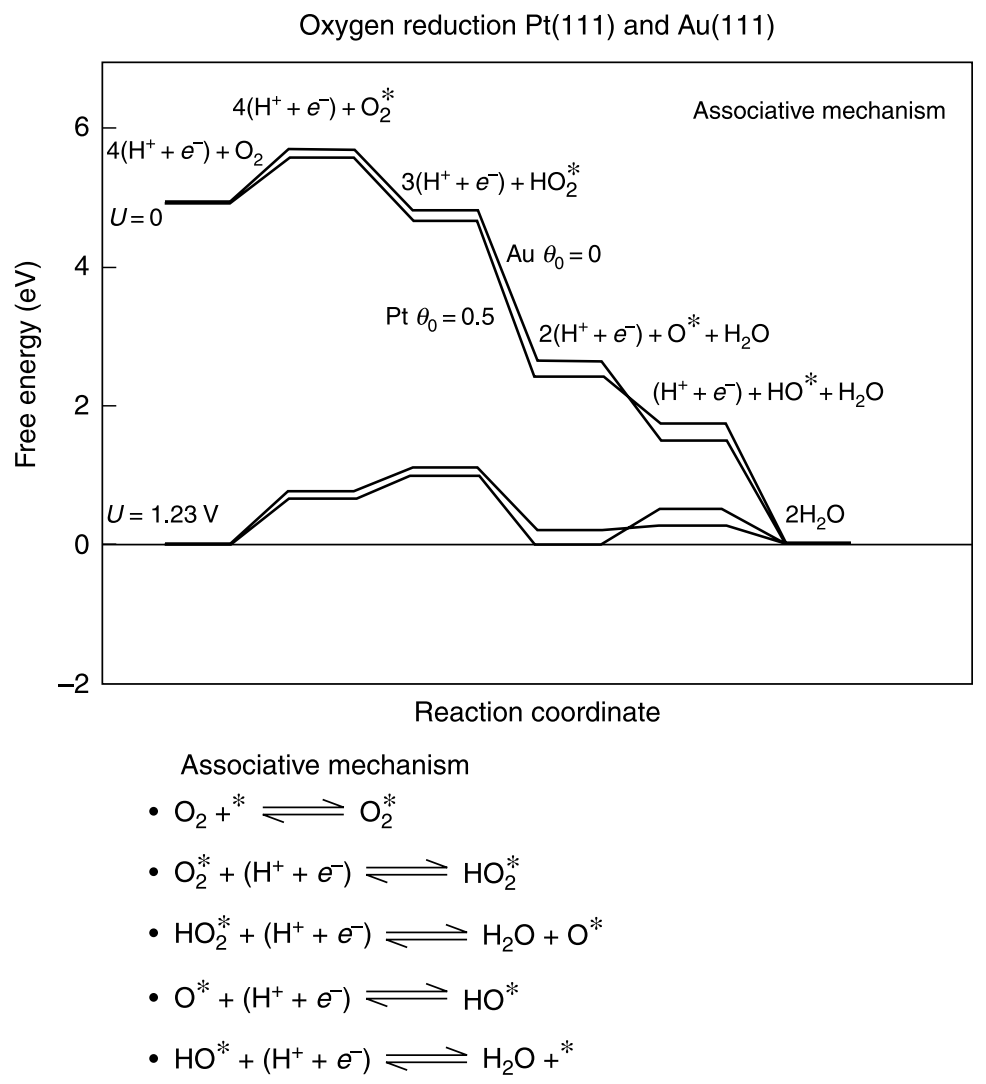

Figure 1.2 Free energy map for the "associative mechanism" of ORR at Pt metal and the steps considered in this mechanism [Nørskov et al., 2004]. 
With the four-electron ORR process in the fuel cell cathode well recognized as the principal challenge at both the theoretical and experimental/technical levels, it is interesting to examine the effects of the most recent theoretical developments on the fundamental understanding of ORR electrocatalysis. Such examination would naturally focus on the nature and quality of the links with experimental work, as reflected by:

- Predictive abilities regarding future promising directions in pursuit of more active ORR electrocatalysts;

- Elucidation of the actual values of key diagnostic parameters that have been used for a long time by ORR experimentalists, including primarily the measured "Tafel slope" and the reaction order with regard to $\mathrm{O}_{2}$, and their predictive power regarding the ORR mechanism.

Starting with predictive abilities of ORR activity, although DFT calculations have provided a much more accurate map of the free energy of formation and free energy of conversion of the possible intermediates in the ORR in acid electrolytes [Nørskov et al., 2004], the tool used for prediction of the ORR rate at the surface of some metal or alloy has remained very simple when considering the complexity of the ORR process. The $\mathrm{M}-\mathrm{OH}$ and/or $\mathrm{M}-\mathrm{O}$ bond strength, proposed as a yardstick for the expected ORR rate at the surface of a metal M, seems to explain the tendencies observed in ORR measured rates at various metal surfaces. This dependence is characterized by a "volcano"-shaped plot of ORR rate versus $\mathrm{M}-\mathrm{O}$ or $\mathrm{M}-\mathrm{OH}$ bond, presented many years ago, albeit using less accurate values for ORR rates. The metal surfaces at the top of the "volcano" correspond to the optimized M-Ox bond strength enabling the highest ORR activity, with the metals on the ascending branch of the plot having bonds to surface oxygen that are too strong to allow further activity as ORR intermediate, and metals on the descending branch having affinity to surface oxygen which is insufficient to activate the dioxygen molecule. While intuitively compelling, a challenge to such a simple yardstick is to provide a sound justification for the predictive power it seems to have for a complex, multistep process like the ORR (a question in this spirit was raised by W. Schmickler in a discussion during the Leiden meeting).

Another challenge stands in the way of attempts to evaluate new theoretical insights into the mechanism of the ORR in light of Tafel slopes and reaction orders reported for the $\mathrm{Pt} /$ hydrous poly\{PFSA\} interface: as late as 2006, results of measurements of these experimental parameters reported from different sources have been in strong apparent disagreement. In the following discussion, an explanation is offered for the origin of such apparent disagreements between various reported Tafel slopes and reaction orders for the ORR at Pt. These disagreements can be reconciled through a proper description of the actual catalyst surface in a PEFC cathode employing a Pt catalyst. The same, fuller description of the cathode catalyst surface in an operating fuel cell also sheds a different light on the possible origin of the power of the $\mathrm{M}-\mathrm{Ox}$ bond strength to predict rates of ORR at different metal catalyst surfaces. 
Mechanistic conclusions from DFT calculations: The recent DFT calculations aided in the clarification of the relative probabilities of various proposed multistep ORR routes from reactant $\mathrm{O}_{2}$ to product $\mathrm{H}_{2} \mathrm{O}$. This has been enabled by the accurate calculation of formation energies for relevant intermediates in any mechanism considered, where the interactions of an intermediate with both the Pt metal surface and the adjacent molecular layers of water are both considered. For example, the probability that the first step in the ORR process is direct, dissociative chemisorption of $\mathrm{O}_{2}$ to form two $\mathrm{O}_{\text {ads }}$ species on the Pt metal surface appears to be low, not only in light of the low rates of this process at the Pt/oxygen gas interface at such low temperatures, but also in light of the deep energy sink associated with chemisorption of an oxygen atom on Pt [Nørskov et al., 2004]. Accordingly, there seems to be an advantage for the ORR route starting with a single electron and proton transfer to $\mathrm{O}_{2}$ to generate the $\mathrm{HOO}_{\text {ads }}$ intermediate and thereby facilitate subsequent breaking of the $\mathrm{O}-\mathrm{O}$ bond, which in $\mathrm{HOO}_{\text {ads }}$ has an order significantly lower than 2 [Panchenko et al., 2004]. $\mathrm{OH}_{\mathrm{ads}}$, rather than $\mathrm{O}_{\mathrm{ads}}$, seems the likely next intermediate on the way to the final $\mathrm{H}_{2} \mathrm{O}$ product, as can be concluded, again, from the deep energy sink associated with $\mathrm{O}_{\text {ads }}$ on Pt. The recent DFT calculations further support the $\mathrm{O}_{2}$-to- $\mathrm{OOH}_{\text {ads }}$-to- $\mathrm{OH}_{\text {ads }}$ route by showing that $\mathrm{OOH}$ is indeed an intermediate of significant bonding energy to Pt, at least on some Pt crystal surfaces [Panchenko et al., 2004]. Another important contribution of the theoretical calculations has been in providing an explanation for the higher measured ORR activity of Pt-alloy catalysts versus unalloyed $\mathrm{Pt}$. In accordance with the premise that the $\mathrm{M}-\mathrm{Ox}$ bond strength is an effective yardstick for predicting relative ORR rates at metal/electrolyte interfaces, the key to the higher ORR activity observed following proper alloying of Pt seems to be the calculated increase in $d$-band vacancy which causes reduction in the affinity of Pt surface sites to chemisorbed $\mathrm{OH}$ or $\mathrm{O}$ species.

Paradoxically, all these significant recent contributions to the theory of the ORR, together with most recent experimental efforts to characterize the ORR at a fuel cell cathode catalyst, have not led at all to a consensus on either the mechanism of the ORR at Pt catalysts in acid electrolytes or even on how to properly determine this mechanism with available experimental tools. To elucidate the present mismatch of central pieces in the ORR puzzle, one can start from the identification of the slow step in the ORR sequence. With the $\mathrm{O}_{2}$-to- $-\mathrm{HOO}_{\text {ads }}$-to- $\mathrm{HO}_{\text {ads }}$ route appearing from recent DFT calculations to be the likely mechanism for the ORR at a Pt metal catalyst surface in acid electrolyte, the first electron and proton transfer to dioxygen, according to the reaction

$$
\mathrm{O}_{2}+\mathrm{H}^{+}+e^{-} \longrightarrow \mathrm{OOH}_{\mathrm{ads}}
$$

becomes the likely slow step that determines the overall interfacial ORR rate at a $\mathrm{Pt}$ catalyst. One reason for this tentative assignment is the demanding requirement of forming a significant bond to the $\mathrm{Pt}$ catalyst surface before $\mathrm{O}-\mathrm{O}$ dissociation can take place - a requirement that can apparently be fulfilled on Pt surface sites of specific atomic geometries, available on some Pt crystal surfaces [Panchenko et al., 2004]. The second reason for assigning (1.2) as the slow step is the results of past experimental 
determinations of the reaction order with respect to $\mathrm{O}_{2}$ and the Tafel slope for the ORR at $\mathrm{Pt}$ in acid electrolytes. A reaction order of (or slightly under) 1.0 and a Tafel slope near $120 \mathrm{mV} /$ decade, measured in the potential range where the Pt surface is practically free of chemisorbed oxygen, are both in agreement with the Reaction (1.2) as the slow step in the ORR sequence. Such measured Tafel slope is expected for a first, one-electron-transfer process like (1.2), when $\alpha$, the "symmetry factor" in the electrochemical rate equation, has a value of 0.5 . Such a value of $\alpha$ means that the change in activation energy in the Reaction (1.2) per some increase in overpotential is $50 \%$ of the corresponding change in the reaction free energy, i.e., $\left\{\delta\left(\Delta G^{\#}\right) / \delta V\right\} /\{\delta(\Delta G) / \delta V\}=$ 0.5 . There is no a priori reason to expect this specific value for $\alpha$; however, a value of 0.5 for what is basically a "Brønsted factor" that describes $\delta\left(\Delta G^{\#}\right)$ as some constant fraction of $\delta(\Delta G)$ is commonly found in electrochemical reactions. Consequently, the reported Tafel slope of $120 \mathrm{mV} /$ decade of current density seems to be in accordance with the first, one-electron-transfer step being the slow step in the ORR sequence, as does the first order in oxygen partial pressure documented for the ORR at the $\mathrm{Pt}$ / hydrated ionomer interface [Parthasarathy et al., 1992a, b].

It would seem that to test the predictive power of recent theoretical work with regard to the ORR mechanism at Pt in acid electrolytes, the Tafel slope predicted by theory should be compared with a reported value of $120 \mathrm{mV} /$ decade measured for ORR at Pt metal, whereas the reaction order predicted by theory be compared with the reported value of, or slightly below 1.0 [Parthasarathy et al., 1992a, b]. However, testing of the recent theoretical predictions against these two experimentally measured parameters has just become complicated by recent reports suggesting strong disagreement between Tafel slopes and reaction orders reported previously from measurements of ORR kinetics at rotating disk or other, ionomer-filmed bulk Pt electrodes and the slope and reaction order measured for cathodes in an operating PEFC. In one such recent experimental report [Neyerlin et al., 2006], the conclusion offered was that, for a fuel cell cathode employing a $\mathrm{Pt} / \mathrm{C}$ catalyst, the full description of ORR kinetics in the potential range relevant to fuel cell operation should be based on a constant Tafel slope of $60 \mathrm{mV} /$ decade of current density and on a reaction order with respect to oxygen of 0.5 . Such reports of a measured constant slope of $60 \mathrm{mV} /$ decade for ORR at the temperatures of an operating PEFC and in the potential range relevant to fuel cell operation have been identified by theorists [Nørskov et al., 2004] as experimental support for a conjecture that the rate-determining step in the ORR may be a single electron and proton transfer to an $\mathrm{OH}_{\mathrm{ads}}$ or $\mathrm{O}_{\mathrm{ads}}$ surface intermediate. According to that conjecture, this step is likely to be rate-determining in light of the significant energy sink from which these intermediates need to be lifted to complete the four-electron process [Nørskov et al., 2004]. The latter authors did not address, however, one consequence expected of a rate-determining step located lower in the sequence of one-electron steps in the ORR process, namely that the reaction order with respect to $\mathrm{O}_{2}$ should then be 0.5 , rather than 1.0 consistently reported from ORR investigations at model, Pt/electrolyte interfaces, including the Pt/hydrated Nafion interface [Parthasarathy et al., 1992a, b]. As if to strengthen the growing question mark regarding widely accepted values of key ORR kinetic parameters, subsequent to the 2004 ORR theoretical paper [Nørskov 
et al., 2004] came the 2006 ORR experimental paper [Neyerlin et al., 2006] and provided apparent support for an ORR reaction order of 0.5 with respect to $\mathrm{O}_{2}$ from measurements done on Pt catalyst in the PEFC cathode. This combination of reports from experimental ORR studies [Neyerlin et al., 2006] and from a theoretical study of the ORR in acid electrolytes [Nørskov et al., 2004], thus seemed to provide significant evidence against the assignment of the Reaction (1.2) as the rate-determining step in the ORR.

The apparent challenges presented by these recent readings of experimental ORR results, winning early support from a DFT study, have left some important questions to answer:

- What is behind the apparent disagreements between Tafel slopes and reaction orders reported from recent investigations of the ORR at PEFC cathode catalysts and the slopes and reaction orders measured earlier for model systems of low Pt surface area? Is the ORR process at a dispersed Pt catalyst possibly different in nature from the ORR process at low-surface-area Pt?

- Can an ORR mechanism at Pt metal in an acid electrolyte with the Reaction (1.2) as the first and rate-limiting step be defended in light of the recently reported apparent Tafel slope and reaction order for ORR in the PEFC cathode?

- With the remaining question marks regarding the mechanism of the ORR and the nature of the slow step in the ORR, does the viability of the simple yardstick ( $\mathrm{M}-\mathrm{OH}$ or $\mathrm{M}-\mathrm{O}$ bond strength), offered for predicting the rate of the complex ORR process [Nørskov et al., 2004] remain unscathed? Or does its predictive power possibly depend strongly on the rate-limiting step being reduction of surface oxygen intermediates [Nørskov et al., 2004], rather than the Reaction (1.2)?

One point that should be raised before trying to answer the above questions is the actual significance of reconciliation between new information and understanding at the atomic and molecular level, as provided by DFT calculations, and "old-fashioned" macroscopic parameters such as the Tafel slope and the reaction order. Arguments have been made, including at the Leiden meeting, to the effect that such macroscopic parameters should not be considered legitimate diagnostic tools in the age of advanced calculations of interfacial electronic structures. The experience of the present author in critically reviewing very recent ORR work, both theoretical and experimental, has led to a renewed conviction that those "old-fashioned" parameters have significant value and should, in fact, be considered carefully in theoretical work done at the atomic/molecular level.

\subsection{DOCUMENTED INFORMATION ON THE ACTUAL NATURE OF THE SURFACE OF A Pt CATALYST IN THE CATHODE OF AN OPERATING FUEL CELL}

Proper answers to the above questions can be provided once it is realized that the surface of the catalyst in a fuel cell cathode using a $\mathrm{Pt}$ or $\mathrm{Pt} / \mathrm{C}$ catalyst cannot be 
described for the purposes of either theory or diagnostics as "Pt metal." While Pt surface coverage by chemisorbed oxygen species at cathode potentials higher than $0.75 \mathrm{~V}$ has been recognized, at least to a degree, in ORR studies, in most examinations of ORR kinetics at "Pt," it has been considered mostly as an afterthought, rather than the major factor it really is in determining the ORR rate and, in fact, in defining the documented dependence of the ORR rate on the M-Ox bond strength. As ORR takes place at "Pt," parallel interfacial processes that need highlighting in ORR diagnostics are driven by the substantial reactivity of the Pt surface with water and with dioxygen. Such processes cause potential- and time-dependent modification of the interfacial composition and structure of an ORR cathode. A recent study by Paik et al. [2004] highlights the significant reactivity of a Pt metal surface in a PEFC cathode under fuel cell cathode operation conditions, bringing about slow build-up of $\mathrm{Pt}$ surface $\mathrm{OH}_{\mathrm{ads}}$ and/or $\mathrm{O}_{\mathrm{ads}}$, above and beyond that measured under ordinary cyclic voltammetry conditions in an inert atmosphere. The coverage of a Pt catalyst surface by chemisorbed oxygen species under a set, constant cathode potential can be estimated from the charge passed during a cathodic potential scan following some timed exposure of the catalyst surface to an oxidizing gaseous atmosphere as shown in Fig. 1.3. As amply documented, Pt is covered by a chemisorbed oxygen species through the potential domain relevant for a fuel cell cathode, even in the complete absence of dioxygen, and this chemisorbed species which is formed by water discharge is quite irreversibly reduced. As seen in Fig. 1.3, the surface oxygen coverage at some cathode potential could actually grow substantially further when dioxygen is introduced into the system. The extra growth in oxide coverage following introduction of $\mathrm{O}_{2}$ is most substantial at $0.85 \mathrm{~V}$ and significantly lower at $0.95 \mathrm{~V}$. This suggests that the extra chemisorbed oxygen species probably forms on Pt metal by a mechanism different than the one operative in the absence of dioxygen. The extra "chemical" surface oxidation process is apparently inoperative when the surface population of metal sites is too low, as would be the case when the applied potential is $0.95 \mathrm{~V}$ or above.

The Pt surface electro-oxidation process observed in the absence of dioxygen to form chemisorbed $\mathrm{OH}$ from water is driven by the potential difference at the $\mathrm{Pt}$ / electrolyte interface, according to the reaction

$$
\mathrm{H}_{2} \mathrm{O}_{\mathrm{ads}} \longrightarrow \mathrm{OH}_{\mathrm{ads}}+\mathrm{H}^{+}+e^{-}
$$

whereas the additional surface oxygen collected on adding dioxygen at an electrode potential around $0.85 \mathrm{~V}$, is likely driven by $\mathrm{O}_{2}$ reduction at surface metal sites, according to the reaction

$$
\begin{aligned}
& \text { (a) } \frac{1}{2} \mathrm{O}_{2}+2 \mathrm{H}^{+}+2 e^{-} \longrightarrow \mathrm{H}_{2} \mathrm{O} \\
& +\quad \text { (b) } 2 \mathrm{H}_{2} \mathrm{O}_{\mathrm{ads}} \longrightarrow 2 \mathrm{OH}_{\mathrm{ads}}+2 \mathrm{H}^{+}+2 e^{-} \\
& \frac{1}{2} \mathrm{O}_{2}+\mathrm{H}_{2} \mathrm{O}_{\mathrm{ads}} \longrightarrow 2 \mathrm{OH}_{\mathrm{ads}}
\end{aligned}
$$



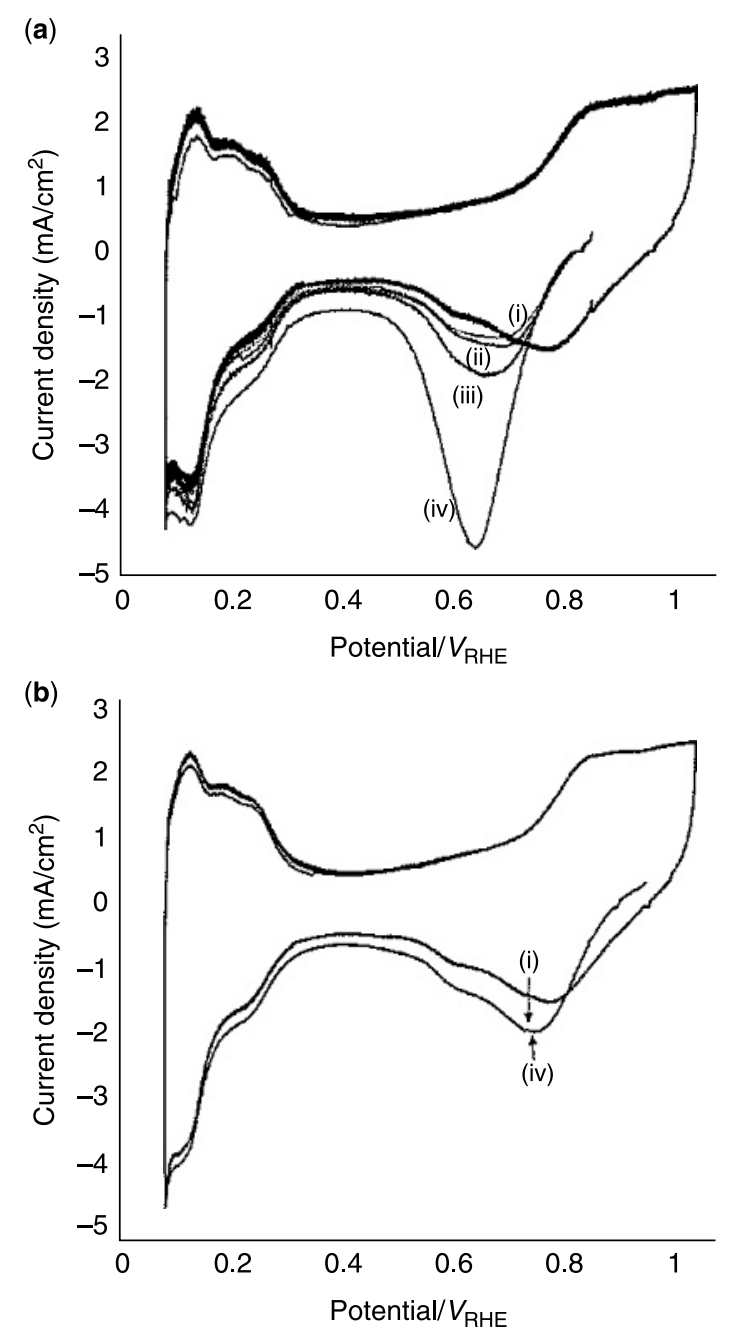

Figure 1.3 Pt catalyst coverage by chemisorbed oxygen species (for $\mathrm{Pt} / \mathrm{C}$ in a PEFC cathode at $25^{\circ} \mathrm{C}$ ): (a) $0.85 \mathrm{~V}, 3 \mathrm{~h}$ of exposure to $\mathrm{N}_{2}, 4 \% \mathrm{O}_{2}$ in $\mathrm{N}_{2}$ and air, and 30 min exposure to $\mathrm{O}_{2}$; (b) $0.95 \mathrm{~V}, 3 \mathrm{~h}$ exposure to $\mathrm{N}_{2}$ and 30 min exposure to $\mathrm{O}_{2}$. From Paik et al. [2004].

Considering the standard potential of $1.23 \mathrm{~V}$ associated with Reaction (1.4a), it can be understood why a dioxygen molecule can be more reactive in the formation of $\mathrm{OH}_{\mathrm{ads}}$ by water oxidation (1.4) than the purely anodic discharge of water driven by a potential of $0.85 \mathrm{~V}$ in an oxygen-free atmosphere. Interestingly, dissociative chemisorption of $\mathrm{O}_{2}$ from the gas phase at Pt-group metal surfaces is reported to be strongly accelerated in the presence of water vapor [Weaver, 2002], suggesting a surface oxidation process involving dioxygen and surface water molecules, identical or similar to the Reaction (1.4). As Fig. 1.3 suggests, Reaction (1.4) apparently takes place at cathode potentials 
over $0.75 \mathrm{~V}$ but under $0.95 \mathrm{~V}$, such that coverage by the $\mathrm{OH}_{\text {ads }}$ formed by the Reaction (1.3) is still incomplete, enabling ORR activity (1.4a) at some non-oxidized (water-covered) Pt metal sites.

The lesson to be taken from this report by Paik et al. [2004] is that a Pt catalyst in contact with a hydrous electrolyte is so active in forming chemisorbed oxygen at temperatures and potentials relevant to an operating PEFC, that the description of the cathode catalyst surface as "Pt," implying "Pt metal," is seriously flawed. Indeed, that a Reaction (1.4) actually takes place at a Pt catalyst surface, "exposes," Pt to be less noble than usually considered (although it remains a precious metal nevertheless ...). Such a surface oxidation process, taking place on exposure to $\mathrm{O}_{2}$ and water and driven by electronically shorted ORR cathode site and metal anode site, is ordinarily associated with surface oxidation (and corrosion) of the less noble metals.

Turning next to the effect of these catalyst surface oxidation processes on the rate of ORR at "Pt", it has been well established that the chemisorbed oxygen species is an inhibitor of the ORR at a "Pt" catalyst surface, as would be expected for any process that requires Pt metal sites to proceed. This has been repeatedly demonstrated experimentally and should be readily understood from theoretical considerations, including the notion of optimized $\mathrm{M}-\mathrm{Ox}$ bond strength as a yardstick for the rate of ORR where $\mathrm{M}$ is a metal surface site. One direct experimental demonstration of this inhibiting effect is the observed continuous PEFC performance reduction on extended operation time scales, shown to be caused by the continuous build-up of chemisorbed oxygen [Eickes et al., 2006], likely formed by both Reactions (1.3) and (1.4). The chemisorbed oxygen formed practically instantaneously on a Pt surface by Reaction (1.3), for example during a potential sweep at several millivolts per second into the "Pt oxide region," is itself well documented to be an ORR inhibitor. This is readily seen from higher ORR currents measured in the fuel-cell-relevant potential domain $(>0.75 \mathrm{~V})$ during the anodic half-cycle of a triangular potential scan $(1.2 \mathrm{~V}-$ $0.4 \mathrm{~V}-1.2 \mathrm{~V}$ ) [Eickes et al., 2006]. During the cathodic half-cycle, the Pt surface is still covered at $V>0.75 \mathrm{~V}$ by (irreversibly reduced) chemisorbed oxygen species formed by the Reaction (1.3) at the high end potential (1.2 V), whereas the anodic half-cycle starts from a low potential of $0.4 \mathrm{~V}$ where all the chemisorbed oxygen has been reductively removed, and, consequently, the coverage by this inhibiting species is quite small when the fuel-cell-relevant potential domain is traversed, resulting in higher observed ORR currents.

With these documented experimental findings and the clear understanding of the criticality of metal sites free of chemisorbed oxygen for ORR catalysis, it remains to be explained why any analysis of the ORR process at Pt catalysts would consider a purely metallic Pt catalyst surface in contact with surface water molecules as the relevant interface. In some cases, this could have been a choice made consciously, aiming to reduce the complexity of the system addressed by leaving full consideration of the actual state of the Pt catalyst surface for later. However, one other factor could have been insufficient knowledge of earlier literature, covering significant efforts to characterize and study the formation of surface and subsurface oxygen on $\mathrm{Pt}$ as function of $\mathrm{Pt}$ electrode potential, temperature, and time. The latter work was done to a large degree by Conway and co-workers in the 1970s and 1980s. Conway et al. reported that the 
long-term potentiostatic build-up of surface oxide charge on Pt (in an inert atmosphere) was proportional to the logarithm of the time, and suggested the schematic description shown in Fig. 1.4 for processes at the atomic scale on and in the Pt surface, when holding the Pt sample at a constant positive potential for extended periods of time. The figure is just a schematic; however, it can serve as a basis for consideration of two important factors. One is identification of the origin of the irreversible reduction of chemisorbed oxygen on $\mathrm{Pt}$ (and the $Q_{\text {oxide }}$ versus $\log$ (time) rate law documented) as a "place exchange" process between chemisorbed oxygen atoms (or $\mathrm{OH}_{\mathrm{ads}}$ ) and surface Pt atoms. This type of process can be understood as an early step in the formation of a three-dimensional oxide phase from the very initial state of oxygen chemisorption on the metal surface. According to Conway et al. [1990], the place exchange process described schematically in Fig. 1.4 results in the conversion of an initial sub-monoatomic layer of chemisorbed oxygen on top of a Pt metal surface into a structure of mixed layers of $\mathrm{Pt}$ and oxygen atoms (or $\mathrm{OH}$ groups). In line with this reasoning, the outer surface of a "Pt" catalyst in a PEFC cathode, particularly following longterm exposure to high potentials at elevated temperatures, could in fact be a mixed $\mathrm{Pt} /$ oxygen atomic layer.

Figure 1.4 also highlights the possibility of a significant range of $\mathrm{Pt}-\mathrm{OH}$ bond strengths, considering on one end of the spectrum the $\mathrm{OH}$ groups well surrounded by metal atoms and, at the other end, $\mathrm{OH}$ groups on top of Pt surface atoms, likely corresponding to those "last formed" surface $\mathrm{OH}$ groups that have not undergone further reorganization into a more stable sub-monolayer lattice of adsorbed intermediates, not to mention insertion under the metal skin. The latter type of $\mathrm{OH}$ species was identified

(a)

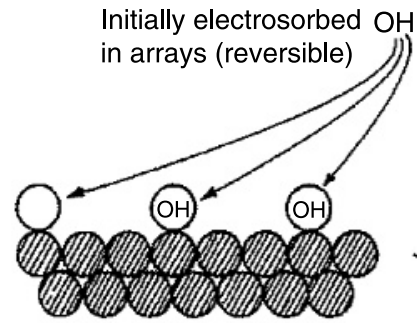

(c)

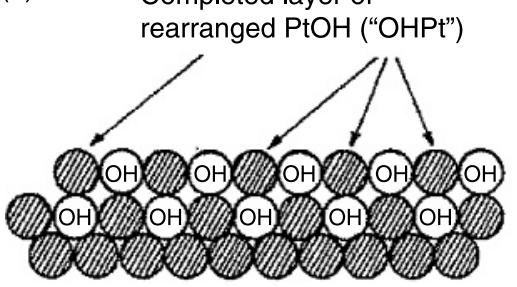

(b) Reversible $\mathrm{OH}$

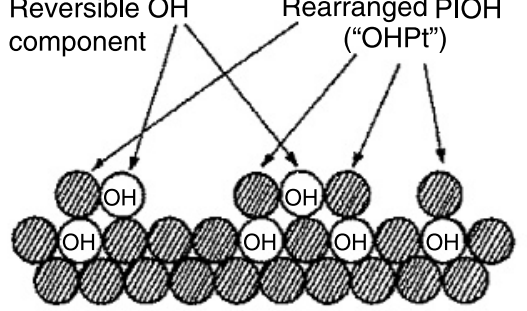

(d) Oxidation toward "OPt" from "OHPt" by $\mathrm{H}^{+}, e^{-}$transfer

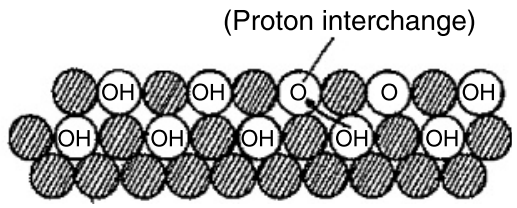

Figure 1.4 Proposed steps in the chemisorption of $\mathrm{OH}$ on/in $\mathrm{Pt}$, starting with arrays of $\mathrm{OH}$ groups over the uppermost metal atom layer, increasing the coordination number of the adsorbed $\mathrm{OH}$ by place exchange, and next generating a mixed, metal/oxygen overlayer while further oxidizing to form O atoms. From Conway et al. [1990]. 
[Conway et al., 1990] as "reversible $\mathrm{OH}$ groups," implying a fast $\mathrm{OH}_{\mathrm{ads}}$ formation/ reduction cycle - a property not shared by the majority of surface oxygen on Pt, which requires a significant cathodic overpotential to be electroreduced. Such surface oxygen groups (the majority) have either been anodically deposited directly on surface sites providing higher coordination (e.g., steps) or have achieved a state of lower energy by surface migration and/or place exchange. The presence of a much more "reversible component of $\mathrm{OH}_{\text {ads }}$ " was concluded by Conway and co-workers from measurements of frequency-dependent pseudocapacitance at Pt at potentials above $0.75 \mathrm{~V}$ [Conway et al., 1990], and Pt surface coverage by this "reversible" type of $\mathrm{OH}_{\text {ads }}$ was determined to be near $10 \%$ of the total surface oxygen species. This insight, provided back in the 1980s, reveals that chemisorbed oxygen, or chemisorbed $\mathrm{OH}$ on $\mathrm{Pt}$, can exhibit a wide range of bond strengths to metal surface atoms, with only a small population of (likely "newly formed"), surface $\mathrm{OH}$ groups being associated with a relatively high rate of reduction, i.e., having the characteristics expected of an active surface intermediate in a faradaic process.

A distribution of adsorption energies of chemically identical surface species formed on a metal electrocatalyst, with a large fraction playing "spectator" and/or "site blocking" roles and only a small fraction being active intermediates in a faradaic process, is not a situation unique to chemisorbed oxygen species and the ORR process at Pt. A recent analysis of the hydrogen oxidation process on Pt reveals a similar situation, as described by Wang et al. [2006].

\subsection{IMPACTS OF THE ACTUAL STATE OF THE CATALYST SURFACE ON THE RATE OF THE ORR AT "Pt"}

To evaluate the effects of the actual nature of a "Pt" catalyst surface on measured ORR characteristics, one has to abandon the prevailing assumption that measured changes of the ORR rate with potential, or with oxygen pressure, can be properly analyzed based on a conceptual model of a catalyst surface of invariable composition, ordinarily assumed to be Pt metal. To evaluate the Tafel slope expected for the ORR at "Pt" in the potential range $0.90-0.75 \mathrm{~V}$, the variation with potential of the surface coverage by blocking chemisorbed oxygen species must be considered, in addition to the "classical" effect of enhancement of the rate of the ORR at Pt metal sites with increased cathode overpotential [Uribe et al., 1992; Wang et al., 2004]. In an early treatment of the expected combined effects of cathodic polarization in (i) removing blocking surface oxide species and (ii) enhancing the rate of ORR at "free" Pt metal sites available on the surface, Uribe et al. [1992] used the following assumptions:

- The ORR at Pt metal sites has a rate dependence on potential described by a Tafel slope of $120 \mathrm{mV} /$ decade (as determined for Pt model systems at high cathodic overpotential, where Pt is practically surface oxide-free [Parthasarathy et al., 1992a, b]).

- The effect of the surface oxide species on the rate of the ORR is explained by metal site blocking, and can be described mathematically by including a $1-\theta_{\mathrm{ox}}$ term in the pre-exponential factor of the rate expression. 
- Assuming that the electrode has not been left at potentials over $0.75 \mathrm{~V}$ for hours, the variation of $\theta_{\mathrm{ox}}$ with electrode potential can be derived from the voltammetric charge associated with bringing the Pt electrode up from a chemisorbed oxygen-free state to some given potential above $0.75 \mathrm{~V}$. A further assumption required here is on the number of electrons passed per surface oxygen species deposited, and this number was assumed by Uribe et al. [1992] to be 1, corresponding to an $\mathrm{OH}_{\text {ads }}$ intermediate formed on a single Pt surface site by the Reaction (1.3).

The rate expression considering the blocking of active sites by surface oxide can then be written as

$$
J_{\mathrm{ORR}}=J_{0}\left(1-\theta_{\mathrm{ox}}\right) \exp \left(\frac{E^{\mathrm{o}}-E}{b_{\text {int }}}\right)
$$

where $E$ is the cathode potential, $E^{\mathrm{o}}$ is the redox potential for the $\mathrm{O}_{2} / \mathrm{H}_{2} \mathrm{O}$ couple under the relevant operation conditions, $\theta_{\mathrm{ox}}$ is the coverage by chemisorbed oxygen at potential $E$, and $b_{\text {int }}$ is the "intrinsic" value of the ORR Tafel slope that would be measured at a Pt metal surface free of any blocking surface species. The variation of ORR current with Pt cathode overpotential to be expected from (1.5) is given by

$$
\frac{d\left(\log J_{\mathrm{ORR}}\right)}{d\left(E^{\mathrm{o}}-E\right)}=\frac{1}{b_{\mathrm{int}}}+\frac{1}{1-\theta_{\mathrm{ox}}} \frac{d \theta_{\mathrm{ox}}}{d E}
$$

where the dependence of $\theta_{\text {ox }}$ on cathode potential $E$ appears as an additional source of ORR rate variation with potential. The qualitative result of the dependence of surface oxygen coverage on $E_{\text {cath }}$ can be seen from (1.6): the apparent Tafel slope for ORR is expected to be smaller than the intrinsic slope $b_{\text {int }}$, i.e., to be smaller than $120 \mathrm{mV}$ per decade of current density near ambient conditions. Furthermore, when $b_{\text {int }}$ is constant through the relevant potential range, the apparent Tafel slope will not be constant necessarily, as can be realized from the nature of the second term on the right-hand side of (1.6).

It is not difficult to understand the physical picture behind the apparent low Tafel slope expected for the ORR according to (1.5). The two terms on the right-hand side of (1.6) correspond to two contributions to ORR rate enhancement with increase in cathode overpotential: (a) lowering of the activation energy for the ORR process at $\mathrm{Pt}$ metal surface sites and (b) generation of more active (metal) surface sites by reducing the coverage $\theta_{\mathrm{ox}}$ of the ORR-blocking chemisorbed oxygen species. It should be also easy to understand why interpretation of an apparent low Tafel slope, resulting from two different contributions to ORR rate enhancement with cathode overpotential, cannot be presented and further analyzed as if it were the intrinsic Tafel slope for the process at the metal surface. The suggestion by Neyerlin et al. [2006] that a Tafel slope of $60 \mathrm{mV} /$ decade describes well the ORR kinetics at a Pt electrode in the fuel-cell-relevant potential range, and is therefore the value to use in fuel cell cathode diagnostics, is not defensible. A measured, practically constant slope of $60 \mathrm{mV}$ per 
(a)

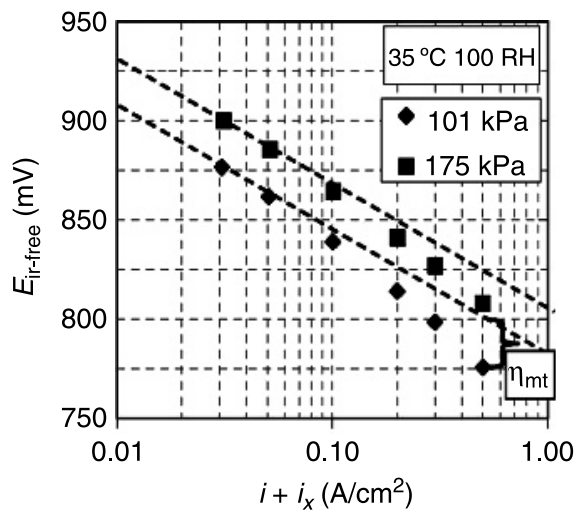

(b)

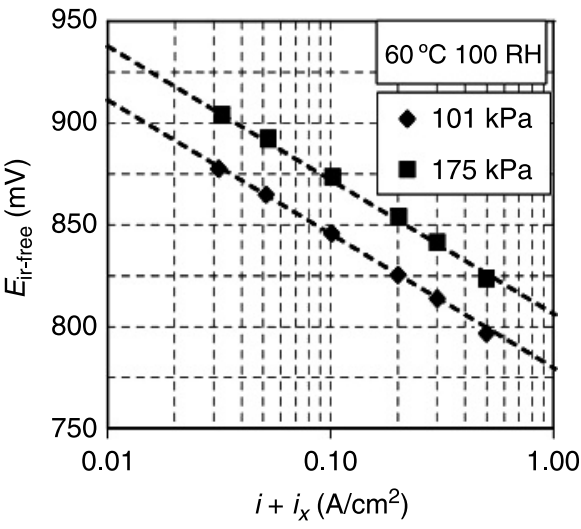

Figure 1.5 The slope of $E_{\text {cath }}$ versus $\log J_{\text {orr }}$ through the fuel-cell-relevant potential range has an apparently constant value near $R T / F$ (measured current density, here designated $i$, is corrected for hydrogen crossover current, designated $i_{x}$, and the measured cell voltage is ir-corrected to provide the cathode potential E) [Neyerlin et al., 2006].

decade of current density has indeed been experimentally established for the process in the PEFC cathode between 0.90 and $0.75 \mathrm{~V}$, as shown in Fig. 1.5 and can obviously be used as some "pragmatic parameter" to describe the PEFC cathode behavior. However, to link it with ORR kinetics at the $\mathrm{Pt} /$ hydrated ionomer interface, an analysis along the lines of the expressions (1.5) and (1.6) is crucial. For one thing, if the apparent Tafel slope is still to provide, as it should, some information on the nature of the slow step in the ORR process, the intrinsic value $b_{\text {int }}$ has to be extracted first from the combined two effects of cathode overpotential as described in (1.6).

To provide quantitative support for the interpretation of the observed Tafel slope in terms of the expression (1.6), one needs to show quantitatively that the experimentally observed behavior, i.e., the apparent slope of about $60 \mathrm{mV} /$ decade in the cathode potential range $0.90-0.75 \mathrm{~V}$, can indeed be the result of an intrinsic slope $b_{\text {int }}$ of $120 \mathrm{mV} /$ decade for ORR at a Pt metal surface, modified for the actual, $\mathrm{Pt} / \mathrm{Pt}-\mathrm{OH}_{\mathrm{ads}}$ mixed surface by the documented variations of $\theta_{\mathrm{ox}}$ with $E$. This was indeed shown by Uribe et al. [1992] using a $\theta_{\text {ox }}$ versus $E$ dependence based on reported voltammetric data [Conway et al., 1990] and an assumption that one electron is passed per surface site in forming an ORR-blocking, chemisorbed oxygen species. The result of that treatment, shown in Fig. 1.6, clearly demonstrates that the observation of a $60 \mathrm{mV} /$ decade Tafel slope for the PEFC cathode between 0.90 and $0.75 \mathrm{~V}$ can be effectively explained by the two combined effects of a change in cathode overpotential as in Equation (1.6). Figure 1.6 also shows that, according to Equation (1.6), the apparent and intrinsic Tafel slopes become identical at high cathode overpotentials, where the coverage by chemisorbed oxygen is negligible and where the second term on the right-hand side of (1.6) goes to zero. Such a rise of the Tafel slope, from near 60 to near $120 \mathrm{mV} /$ decade with increasing overpotential, 


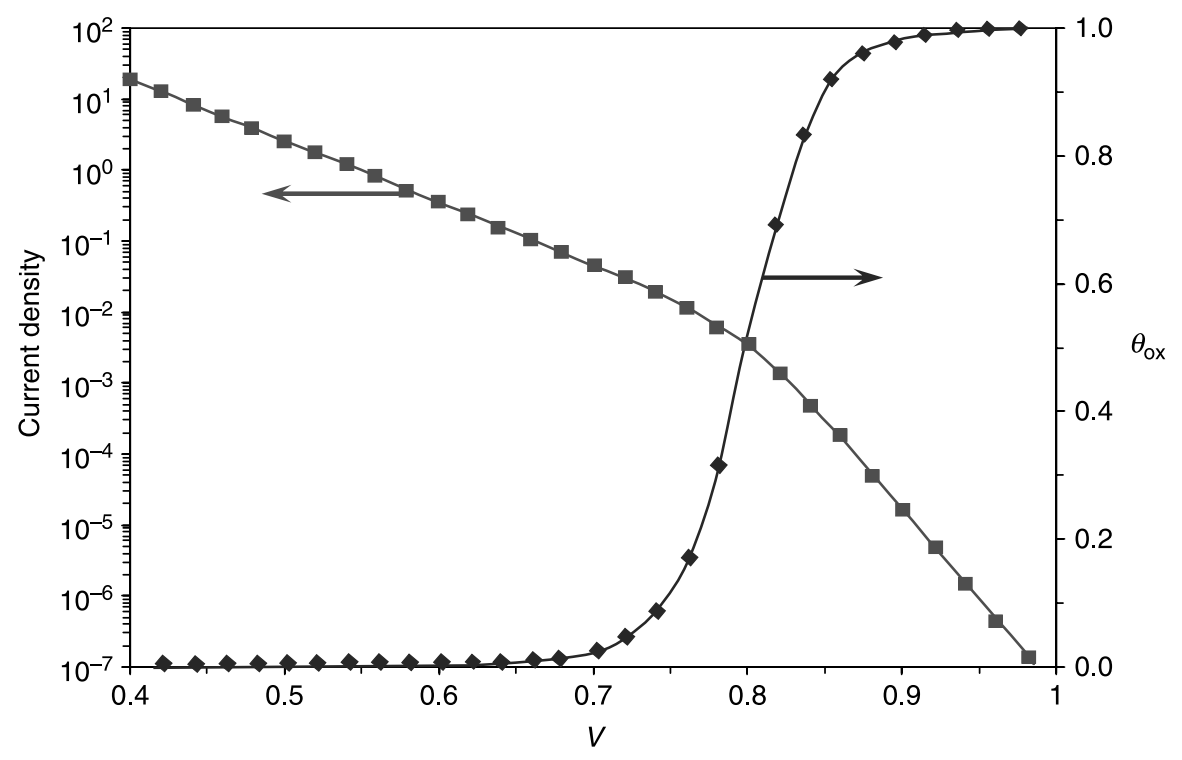

Figure 1.6 The variation of $\log J_{\mathrm{ORR}}$ with $V_{\text {cath }}$ expected based on (1.5), with the coverage by surface oxygen derived from voltammetry [Uribe et al., 1992].

has indeed been observed near ambient conditions in a number of investigations at relevant model Pt/electrolyte interfaces (see, e.g., Parthasarathy et al., 1992a, b).

In this regard, the skepticism expressed by Neyerlin et al. [2006] about the accuracy of mass transport corrections in evaluating ORR kinetic currents, and hence about the Tafel slope reported for the ORR at Pt at cathode potentials below $0.75 \mathrm{~V}$, may be justified for high surface area electrodes, where the rate of the surface process is significantly "amplified" compared with the rate of mass transport processes. However, this criticism does not hold to the same degree for model systems of much lower Pt surface area per geometric electrode area. Consequently, the $120 \mathrm{mV} /$ decade slope consistently reported for mass-transport-corrected ORR currents measured near room temperature at potentials under $0.75 \mathrm{~V}$ at RDEs, can be considered as established data that, with high probability, fully applies to the dispersed Pt metal catalyst in the PEFC. The fuel-cell-relevant potential region (see Fig. 1.5), falls fully within one branch of the complete behavior described by Fig. 1.6, and consequently this low, practically unchanged, value of the Tafel slope measured throughout this limited potential range (see Fig. 1.5) does not challenge the general analysis based on the expression (1.6).

Is there a way to verify experimentally not only that the measured low Tafel slope of $60 \mathrm{mV} /$ decade in the fuel-cell-relevant potential range is fully explainable by an "intrinsic" slope of $120 \mathrm{mV} /$ decade for ORR at Pt metal, but also that this intrinsic Tafel slope can be experimentally verified within the fuel-cell-relevant potential range? In fact, an elegant response to this challenge has recently been provided by impedance spectra measured for the ORR process at $\mathrm{Pt} / \mathrm{C}$ in a PEFC cathode 
[Makharia et al., 2005]. These spectra display a major loop in the $Z^{\prime \prime}$ versus $Z^{\prime}$ plot that cuts the $Z^{\prime}$ axis at some frequency in the range $0.1-1 \mathrm{~Hz}$, followed by an inductive loop that cuts the $Z^{\prime}$ axis again at a much lower frequency. This frequency response of the interfacial faradaic process likely reflects variations of ORR current in response to a cyclic potential perturbation, originating from two effects of the potential on ORR rate, which are well resolved by their different response times. A relevant expression describing this behavior is likely of the form

$$
\frac{d J}{d E}(E, \omega)=\left(\frac{d J}{d E}\right)_{\theta_{\mathrm{ox}}}(E, \omega)+\left(\frac{d J}{d \theta_{\mathrm{ox}}}\right)_{E} \frac{d \theta_{\mathrm{ox}}}{d E}(E, \omega)
$$

This expression suggests that the dependence of the ORR interfacial impedance on potential at a Pt surface of "frozen coverage," corresponding to the first term on the right-hand side, could possibly be measured at perturbation frequencies sufficiently high that the variation of oxide coverage with potential (appearing in the second term) is too slow to follow. The additional contribution of $d \theta_{\mathrm{ox}} / d E$ to the overall impedance measured under DC conditions can then be derived from the additional changes of the measured impedance at lower frequencies, i.e., when $\theta_{\mathrm{ox}}$ follows the slow potential perturbation. Quite strikingly, the variation of the ORR impedance under frozen coverage conditions, derived from variation with $E_{\text {cath }}$ of the diameter of the large loop in Fig. 1.7, corresponded to a Tafel slope close to $120 \mathrm{mV} /$ decade, whereas the apparent Tafel slope under DC conditions, corresponding to the value of $Z^{\prime}$ at the lowest end of the frequency spectrum, was found close to $60 \mathrm{mV}$ (Mark Mathias, personal communication, 2007).

The other challenging ORR finding reported recently and mentioned above was of measured apparent reaction order with respect to oxygen of near 0.5 [Neyerlin et al., 2006]. Added to the suggestion that the measured Tafel slope of $60 \mathrm{mV} /$ decade is representing "ORR kinetics" at Pt fuel cell catalysts above $0.75 \mathrm{~V}$, the report of a reaction order with respect to $\mathrm{O}_{2}$ of 0.5 seemed to support the possibility of the slow step in the ORR belonging further down the ORR sequence, as actually suggested in Nørskov et al. [2004]. Such a slow step could possibly be the reduction of $\mathrm{OH}_{\mathrm{ads}}$ according to

$$
\mathrm{OH}_{\mathrm{ads}}+\mathrm{H}^{+}+e^{-} \longrightarrow \mathrm{H}_{2} \mathrm{O}
$$

Having explained above why the apparent low Tafel slope is, in fact, hiding an intrinsic Tafel slope no smaller than $120 \mathrm{mV} /$ decade, it remains to be seen if the reported reaction order of 0.5 [Neyerlin et al., 2006] can be understood along similar lines. For the purpose of this consideration, it is important to note the experimental conditions employed in Neyerlin et al. [2006] to study the ORR rate dependence on $P_{\mathrm{O}_{2}}$. Unlike previous studies at relevant $\mathrm{Pt} /$ ionomer interfaces, which were performed near room temperature and employed oxygen partial pressures no higher than $1 \mathrm{~atm}$ [Parthasarathy et al., 1992a, b], the most recent study by Neyerlin et al. [2006] used elevated temperatures typical of an operating PEFC and oxygen pressures between 1 and $4 \mathrm{~atm}$. The likely result of such experimental conditions is that an increase in the oxygen pressure again has more than the single effect on the rate of the ORR 


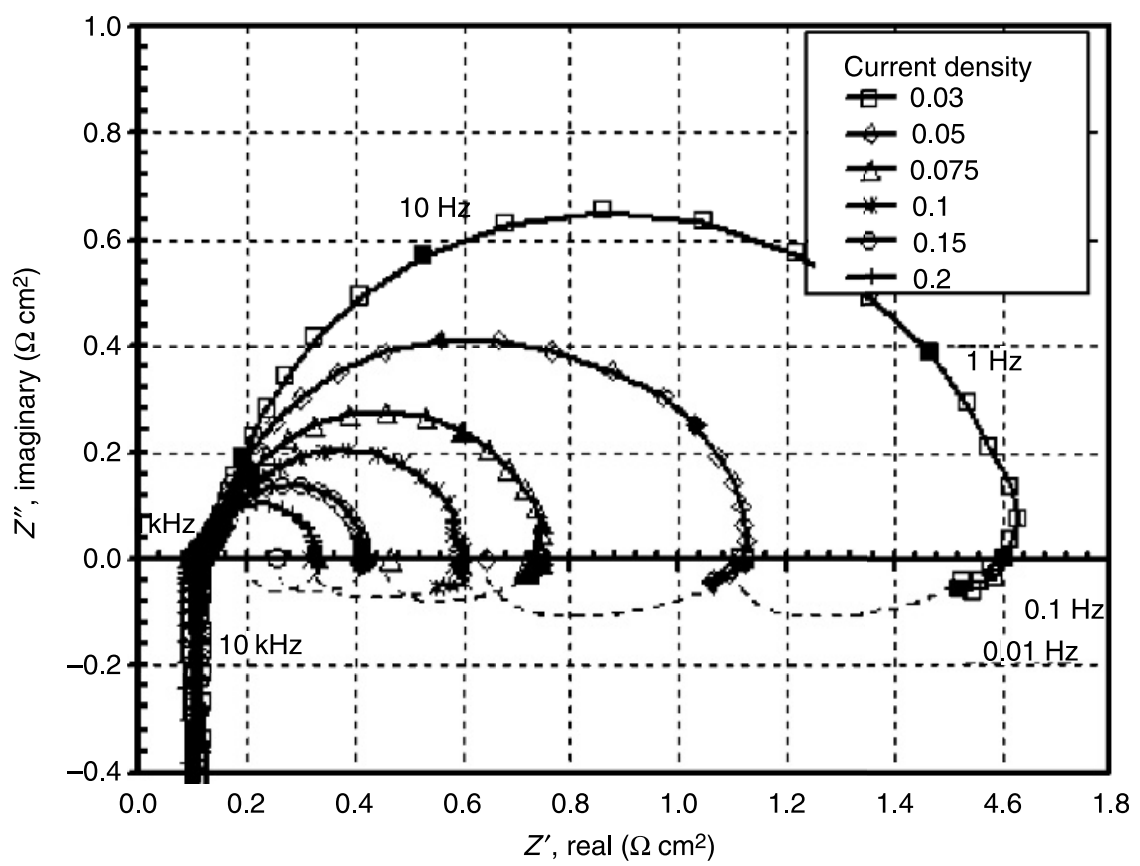

Figure 1.7 ORR impedance plots for a Pt electrode at several cathode DC currents, showing a low frequency branch corresponding to slow increase of the rate (slow lowering of the faradaic impedance) following cathodic perturbation [Makharia et al., 2005].

that is ordinarily considered. This time, the two effects of (i) an enhanced ORR rate at surface metal sites and (ii) changes in catalyst surface composition with increasing $P_{\mathrm{O}_{2}}$ [Paik et al., 2004] will be opposing each other. For a dependence of $J_{\mathrm{ORR}}$ on $P_{\mathrm{O}_{2}}$ at $\mathrm{Pt}$ metal at a constant cathode overpotential $\eta$ described by

$$
J_{\mathrm{ORR}}=J_{0} P_{\mathrm{O}_{2}}^{\gamma}\left(1-\theta_{\mathrm{OX}}\right)
$$

where $J_{0}$ corresponds to the standard state $P_{\mathrm{O}_{2}}=1$ atm, the resulting apparent reaction order will be

$$
\frac{d\left(\log J_{\mathrm{ORR}}\right)}{d\left(\log P_{\mathrm{O}_{2}}\right)}=\gamma-P_{\mathrm{O}_{2}}\left[\frac{1}{1-\theta_{\mathrm{Ox}}}\right]_{\eta}\left[\frac{d \theta_{\mathrm{Ox}}}{d P_{\mathrm{O}_{2}}}\right]_{\eta}
$$

Equation (1.9b) shows that, when the surface coverage by blocking chemisorbed oxygen increases with $P_{\mathrm{O}_{2}}$, the apparent reaction order with respect to $\mathrm{O}_{2}$ is expected to be smaller than the actual intrinsic reaction order with respect to dioxygen, $\gamma$, for ORR at a Pt metal catalyst. An increase in surface coverage by chemisorbed oxygen with enhanced $P_{\mathrm{O}_{2}}$ will likely take place to a larger extent under elevated temperatures and with oxygen pressures of several atmospheres, as used in Neyerlin et al. [2006], possibly leading to an apparent reaction order significantly smaller than reported, 
for example, in Parthasarathy et al. [1992a, b], under much milder conditions with respect to Pt surface oxidation.

\subsection{A COMPREHENSIVE EXPRESSION FOR $J_{\text {ORR }}$ WITH CONSIDERATION OF THE REAL NATURE OF THE CATHODE CATALYST SURFACE}

The ORR rate expression used in most previous ORR studies-theoretical as well as experimental-has not included proper consideration of the actual, potentialdependent catalyst surface composition under relevant PEFC cathode operating conditions. From the discussion above, inclusion of the effect of chemisorbed oxygen species in terms of site blocking, i.e., in terms of lowering of the number of active metal sites available for the ORR, can be seen to be essential for the proper description of ORR in a PEFC cathode. This effect of site blocking belongs in the pre-exponential factor of the rate expression, which includes, in general, a frequency factor that is multiplied by the probability of the surface reaction to generate a fruitful encounter of the reactant molecule with the surface containing the catalytically active sites. Accordingly, an expression that considers the site blocking effect under discussion here will have the form

$$
J_{\mathrm{ORR}}(E)=k N_{\text {total }} P_{\mathrm{O}_{2}}^{\gamma}\left(1-\theta_{\mathrm{ox}}\right) \exp \left(-\frac{\Delta H_{\mathrm{act}}^{*}}{R T}\right) \exp \left(-\frac{E-E_{\mathrm{O}_{2} / \mathrm{H}_{2} \mathrm{O}}^{\mathrm{o}}}{b_{\text {int }}}\right)
$$

where $k$ is a frequency factor, $N_{\text {total }}$ is the total number of active sites, and $\Delta H_{\text {act }}^{*}$ is the activation energy for the (slow step in the) ORR process at $E_{\mathrm{O}_{2} / \mathrm{H}_{2} \mathrm{O}}^{\mathrm{O}}$ with respect to an RHE. In Reaction (1.10), the $1-\theta_{\text {ox }}$ term is included in the pre-exponential factor to describe the effect of site blocking on the probability of fruitful encounters, as has been done previously in Uribe et al. [1992] and Wang et al. [2004]. But the effect of the electrode potential in (1.10) is still confined to the exponential factor, i.e., to the effect of cathode potential on the ORR activation energy at metal sites. In reality, as discussed above, $\theta_{\mathrm{ox}}$ is a function of $E_{\text {cath }}$, and this dependence can be described more explicitly.

As is well documented, formation of chemisorbed oxygen species on a Pt surface at $V>0.75 \mathrm{~V}$ occurs in an inert atmosphere on $\mathrm{Pt}$ in contact with an aqueous, or hydrous polymer electrolyte, by "anodic discharge" of water molecules to form $\mathrm{OH}_{\mathrm{ads}}$ on metal sites, according to the Reaction (1.3). It is this chemisorbed oxygen species, derived from "water discharge," that will be considered in the following discussion. Significantly, the Reaction (1.3) is associated with a redox potential $E_{\mathrm{Pt}\left(\mathrm{H}_{2} \mathrm{O}\right) / \mathrm{Pt}^{\mathrm{O}}-\mathrm{OH}_{\text {ads }}}^{\mathrm{o}}$ which is quite different from the redox potential for the faradaic ORR process, $E_{\mathrm{O}_{2} / \mathrm{H}_{2} \mathrm{O}}^{\mathrm{o}}$. In fact, $E_{\mathrm{Pt}\left(\mathrm{H}_{2} \mathrm{O}\right) / \mathrm{Pt}^{\mathrm{O}}-\mathrm{OH}_{\text {ads }}}^{\mathrm{o}}$ was determined from recent DFT calculations of formation energies for various oxygen species adsorbed on a Pt metal surface. The reported result was $E_{\mathrm{Pt}\left(\mathrm{H}_{2} \mathrm{O}\right) / \mathrm{Pt}-\mathrm{OH}_{\text {ads }}}^{\mathrm{o}}=0.80 \mathrm{~V}$ with respect to an $\mathrm{RHE}$, with $\theta_{\mathrm{OH}}=\frac{1}{3}$ selected to define the standard state [Nørskov et al., 2004]. This calculated value of 
$E_{\mathrm{Pt}\left(\mathrm{H}_{2} \mathrm{O}\right) / \mathrm{Pt}-\mathrm{OH}_{\text {ads }}}^{\mathrm{o}}$ agrees well with voltammetric measurements of the potential corresponding to similar partial coverage by $\mathrm{OH}_{\text {ads }}$ on a $\mathrm{Pt}$ surface in contact with aqueous electrolytes free of strongly adsorbed anions. It can be readily seen that it is the value of the cathode potential with respect to $E_{\mathrm{Pt}\left(\mathrm{H}_{2} \mathrm{O}\right) / \mathrm{Pt}^{\mathrm{O}}-\mathrm{OH}_{\text {ads }}}^{\mathrm{o}}$ (not with respect to $E_{\mathrm{O}_{2} / \mathrm{H}_{2} \mathrm{O}}^{\mathrm{O}}$ ) that determines the value of $1-\theta_{\mathrm{OH}}$ in (1.10). Consequently, to "ignite" the ORR current at $\mathrm{Pt}$, a key requirement is seen to be a pre-exponential factor in (1.10) significantly larger than zero, which requires, in turn that $\theta_{\mathrm{ox}}$ be lowered significantly under 1 by bringing $E_{\text {cath }}$ close to $E_{\mathrm{Pt}\left(\mathrm{H}_{2} \mathrm{O}\right) / \mathrm{Pt}-\mathrm{OH}_{\text {ads }}}^{\mathrm{o}}$, i.e., down from $E_{\mathrm{O}_{2} / \mathrm{H}_{2} \mathrm{O}}^{\mathrm{o}}$ by almost $400 \mathrm{mV}$.

Can this demand for a significant number of metal active sites be further quantified by a general expression in terms of cathode potential demand? The answer is, in principle, yes, although the dependence of the relative populations of metal surface sites and oxidized surface sites on cathode potential could depend on $E-E_{\mathrm{Pt}\left(\mathrm{H}_{2} \mathrm{O}\right) / \mathrm{Pt}-\mathrm{OH}_{\text {ads }}}^{\mathrm{o}}$ in a somewhat different way, depending on the degree to which the free energy of oxygen chemisorption is coverage-dependent. In the simplest case of noninteracting adsorbed species, where the relative populations are determined by a Nernst-type relationship with one electron assumed to be required for conversion of a metal site to an oxide-covered site (and vice versa), the expression for the surface population ratio will be

$$
\frac{\theta_{\mathrm{OH}}}{1-\theta_{\mathrm{OH}}}=\exp \left\{\frac{F}{R T}\left(E-E_{\mathrm{Pt}\left(\mathrm{H}_{2} \mathrm{O}\right) / \mathrm{Pt}-\mathrm{OH}_{\text {ads }}}^{\mathrm{o}}\right)\right\}
$$

A more spread-out dependence of $\mathrm{OH}_{\mathrm{ads}}$ on $E-E_{\mathrm{Pt}\left(\mathrm{H}_{2} \mathrm{O}\right) / \mathrm{Pt}-\mathrm{OH}_{\mathrm{ads}}}^{\mathrm{o}}$ will occur when interaction energies between chemisorbed species become significant; however, it is always the potential difference $E-E_{\mathrm{Pt}\left(\mathrm{H}_{2} \mathrm{O}\right) / \mathrm{Pt}^{-} \mathrm{OH}_{\text {ads }}}^{\mathrm{o}}$ that determines the availability of active metal sites, reflected by the $1-\theta_{\mathrm{OH}}$ term in the pre-exponential factor. The pre-exponential factor can consequently be expressed directly as a function of $E-E_{\mathrm{Pt}\left(\mathrm{H}_{2} \mathrm{O}\right) / \mathrm{Pt}^{-} \mathrm{OH}_{\mathrm{ads}}}^{\mathrm{o}}$ by replacing the $1-\theta_{\mathrm{OH}}$ term in $(1.10)$ by a term derived from (1.11), to yield

$$
J_{\mathrm{ORR}}(E)=k P_{\mathrm{O}_{2}}^{\gamma} N_{\text {total }}\left(\frac{1}{Z+1}\right) \exp \left\{-\frac{\Delta H_{\mathrm{act}}^{*}}{R T}\right\} \exp \left\{-\frac{E-E_{\mathrm{O}_{2} / \mathrm{H}_{2} \mathrm{O}}^{\mathrm{o}}}{b_{\text {int }}}\right\}
$$

where

$$
Z=\exp \left\{\frac{F}{R T}\left(E-E_{\mathrm{Pt}\left(\mathrm{H}_{2} \mathrm{O}\right) / \mathrm{Pt}-\mathrm{OH}_{\mathrm{ads}}}^{\mathrm{o}}\right)\right\}
$$

Equation (1.12) describes an ORR rate dependence on potential that derives from two different redox potentials, one affecting the exponential part of the expression and the other affecting the pre-exponential part. The term depending on $E-E_{\mathrm{O}_{2} / \mathrm{H}_{2} \mathrm{O}}^{\mathrm{o}}$ reflects the lowering of the activation energy at an active metal site by an increase in cathode overpotential, whereas the term depending on $\left(E-E_{\mathrm{Pt}\left(\mathrm{H}_{2} \mathrm{O}\right) / \mathrm{Pt}^{\mathrm{O}}-\mathrm{OH}_{\text {ads }}}^{\mathrm{o}}\right)$ describes the fraction of active metal sites, $(1 / Z+1)$, at some value of $E$. Equation (1.12) suggests 
that it is the value of $E-E_{\mathrm{Pt}\left(\mathrm{H}_{2} \mathrm{O}\right) / \mathrm{Pt}-\mathrm{OH}_{\text {ads }}}^{\mathrm{o}}$ that could be the key for the "ignition" of the ORR current on a gradual increase of the cathode overpotential. The simple-case expression used here for $Z$ yields a ratio of number of metal sites to number of chemisorbed oxygen covered sites of $1: 100$ at $E-E_{\mathrm{Pt}\left(\mathrm{H}_{2} \mathrm{O}\right) / \mathrm{Pt}-\mathrm{OH}_{\mathrm{ads}}}^{\mathrm{O}}=0.12 \mathrm{~V}$, increasing to $1: 10$ at $E-E_{\mathrm{Pt}\left(\mathrm{H}_{2} \mathrm{O}\right) / \mathrm{Pt}^{\mathrm{O}}-\mathrm{OH}_{\text {ads }}}^{\mathrm{o}}=0.06 \mathrm{~V}$. That "ignition" of the ORR process is indeed observed about $0.1 \mathrm{~V}$ positive of $E_{\mathrm{Pt}\left(\mathrm{H}_{2} \mathrm{O}\right) / \mathrm{Pt}^{\mathrm{O}}-\mathrm{OH}_{\text {ads }}}^{\mathrm{O}}$ clearly confirms the criticality of cathodic generation of active metal sites and, consequently, of proper representation of site availability by the $(1 / 1+Z)$ term in (1.12).

\subsection{POSSIBLE DESCRIPTION OF ORR AT A Pt/Pt-Ox CATALYST SURFACE AS A REDOX-MEDIATED PROCESS}

The notion of a surface redox system that determines an "ignition potential" for a faradaic process, including for the ORR, is well recognized in cases where such a surface redox system is added onto a metal or a carbon substrate. For example, to activate the ORR on various high surface area carbon structures, Co and/or Fe ion centers are attached, using appropriate ligation, which affects the standard potential of the redox couple and assists in surface bonding. Redox mediation in cases of such ORR catalysts can be conceptually divided into three steps:

1. A significant steady-state population of reduced surface sites is generated by the cathodic overpotential, as set by the fuel cell load.

2. The reduced sites donate electrons to the reactant oxygen molecule and to intermediates formed, this electron transfer being coupled with bond breaking and making involved in the ORR process.

3. Electrons donated to the surface oxygen species are instantaneously replenished from the ohmic contact to maintain a steady state population of electron-filled (reduced) surface states determined by $E_{\text {cath }}$.

A description of the above sequence in terms of equations for the electrochemical steps takes the form exemplified by the following specific case:

(a) $4 \mathrm{Co}_{\text {surface }}^{+3}+4 e \longrightarrow 4 \mathrm{Co}_{\text {surface }}^{+2}$

(b) $4 \mathrm{Co}_{\text {surface }}^{+2}+\mathrm{O}_{2}+4 \mathrm{H}^{+} \longrightarrow 4 \mathrm{Co}_{\text {surface }}^{+3}+2 \mathrm{H}_{2} \mathrm{O}$

(c) $4 \mathrm{Co}_{\text {surface }}^{+3}+4 e \longrightarrow 4 \mathrm{Co}_{\text {surface }}^{+2} \quad$ [followed by repeat of step (a)]

In such cases of redox mediation, it seems clear why step (a) would maintain a steady state population of reduced sites according to the value of $E-E_{\text {surface redox couple }}^{\mathrm{o}}$, whereas the rate of step (b) will be enhanced with $E-E_{\mathrm{O}_{2} / \mathrm{H}_{2} \mathrm{O}}^{\mathrm{o}}$, the cathode overpotential driving the faradaic four-electron reduction of oxygen. And it is also clear why approaching $E_{\text {surface redox couple }}^{\mathrm{o}}$ could be the prerequisite for "igniting" the ORR 


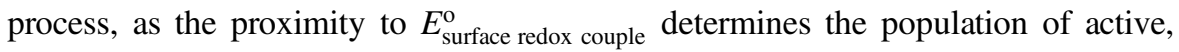
reduced sites, according to

$$
N_{\text {red }}=N_{\text {total }} \frac{1}{Z+1}
$$

where $Z$ is a function of $E-E_{\text {surface redox couple }}^{\mathrm{o}}$

Along the same lines, the population of the active metal sites on a $\mathrm{Pt} / \mathrm{Pt}-\mathrm{Ox}$ catalyst surface can be seen to be well described by (1.15), with the parameter $Z$ being given as $Z=\exp \left\{(F / R T)\left(E-E_{\mathrm{Pt}-\mathrm{OH}_{2} / \mathrm{Pt}-\mathrm{OH}}^{\mathrm{o}}\right)\right\}$, and with the ORR process proceeding along conceptual steps similar to those in the process (1.14), according to

(a) $4 \mathrm{Pt}-\mathrm{OH}_{\text {surface }}+4 \mathrm{H}^{+}+4 e \longrightarrow 4 \mathrm{Pt}_{\text {surface }}+2 \mathrm{H}_{2} \mathrm{O}$

(active reduced site generation)

(b) $4 \mathrm{Pt}_{\text {surface }}+\mathrm{O}_{2}+4 e+4 \mathrm{H}^{+} \longrightarrow 4 \mathrm{Pt}-\mathrm{OH}_{\text {surface }}$

(faradaic reaction of $\mathrm{O}_{2}$ at/with the reduced site followed by

repeat of (A), and so on)

This analogy to a surface redox mediated process is significant. In a way very similar to the reaction sequence (1.14), the standard potential of the redox surface system $\mathrm{Pt}\left(\mathrm{H}_{2} \mathrm{O}\right) / \mathrm{Pt}_{-} \mathrm{OH}_{\text {ads }}(0.80 \mathrm{~V}$ with respect to $\mathrm{RHE})$ determines the active (reduced) site population at any cathode potential $E$, and consequently is the critical parameter in determining the "ignition potential" for the ORR process.

The critical role of the $\mathrm{M} / \mathrm{M}-\mathrm{OH}$ redox system in determining the population of the surface active metal sites is, with high probability, the actual reason for the strong predictive power of the $\mathrm{M}-\mathrm{Ox}$ bond strength with regard to the relative rates of ORR at different "metal" surfaces. In fact, a better presentation of the "volcano plot" would be obtained by using, for the ordinate of the plot the value $(1 / Z+1) \exp \left(-\Delta H_{\mathrm{act}}^{*} / R T\right)$, at a constant cathode potential of interest for fuel cell technology, e.g., $0.85 \mathrm{~V}$, where $\mathrm{Z}$ for a metal $\mathrm{M}$ is given by

$$
Z=\exp \left[\frac{F}{R T}\left(E-E_{\mathrm{M}\left(\mathrm{H}_{2} \mathrm{O}\right) / \mathrm{M}-\mathrm{OH}_{\text {ads }}}^{\mathrm{O}}\right)\right]
$$

For the ascending branch of the volcano plot, the term $(1 / Z+1)$ could serve by itself as an effective ORR activity predictor, whereas, for the descending branch, $(1 / Z+1)$ becomes close to unity at $0.85 \mathrm{~V}$, and the exponential factor $\exp \left(-\Delta H_{\text {act }}^{*} / R T\right)$, then determines the ORR rate based on the residual interaction of dioxygen with the (excessively) noble metal catalyst surface.

The expression $(1 / Z+1)] \exp \left[-\Delta H_{\mathrm{act}}^{*} / R T\right]$ at $0.85 \mathrm{~V}$, better reflects the reality of a partially oxidized Pt surface and the critical effect of active site availability on the rate of the ORR. Effects of site availability were not considered in the calculations in Nørskov et al. [2004] of ORR "activity" for various metals. The expression used to calculate "activity" defined the ordinate parameter in the ORR volcano plots presented. This parameter was defined in Nørskov et al. [2004] as $k T \min _{i} \log \left(k_{i} / k_{\mathrm{o}}\right)$, 
where $k_{i}=v_{i} \exp \left(-E_{\mathrm{a}}^{i} / k T\right)$, with $v_{i}$ a frequency factor and $E_{\mathrm{a}}^{i}$ the activation energy of the slower step, $i$, in the ORR sequence at the metal surface. Nørskov et al. [2004], in fact, explain that such a calculation of "activity" yields a maximum value for the rate expected when the maximum possible surface sites required for the rate-limiting process are all available. The latter means that, for the case of the Reaction (1.2) being the slow ORR step, all surface sites are oxide-free metal sites - an unrealistic assumption even in the case of $\mathrm{Pt}$, not to mention more electropositive metals. It is the site availability effect that dominates the actual activity, rather than the activation energy of the slow step in the faradaic process.

So why then do volcano plots in Nørskov et al. [2004] generate reasonable fits to experiment while completely disregarding the major factor of metal site availability? This is because of the assumption made there that the reduction of surface oxygen is the slow step in the faradaic ORR process. The result is the appearance of the potential associated with the $\mathrm{M} / \mathrm{M}-\mathrm{OH}$ couple in the activation energy of the assumed slow step of the ORR process occurring at metal sites. In reality, however, the significance of the potential of the $\mathrm{M} / \mathrm{M}-\mathrm{OH}$ couple is in determining the active (metal) site availability near $0.9 \mathrm{~V}$, not in determining the rate of the faradaic ORR process at metal sites. The latter sites are, in fact, completely unavailable at the relevant potentials on all metals less noble than $\mathrm{Pt}$ appearing on the ascending branch of the ORR volcano plots.

Using $(1 / Z+1)$ as a gauge of ORR activity therefore also addresses a critical remark frequently raised regarding the applicability of volcano plots based on metal-oxygen bond strengths to those metals that are fully covered by a surface oxide in the relevant cathode potential range, i.e., metals that cannot actually form new $\mathrm{M}-\mathrm{Ox}$ bonds when interacting with dioxygen. Once the value of the preexponential factor $(1 / Z+1)$ appears as part of or as the complete ORR activity yardstick, metals strongly covered by surface oxide at $E_{\text {cath }}>0.75 \mathrm{~V}$ are clearly predicted to exhibit negligible ORR activity, as a direct result of their excessive coverage by surface oxide.

\subsection{SOME CONCLUSIONS}

A description of ORR at "Pt" that disregards the potential-dependent blocking of active metal surface sites is fundamentally unsatisfactory, because it neglects a central physical/chemical feature of the real interfacial system. Furthermore, such descriptions can lead to numerical values and mechanistic conclusions in apparent conflict with understandings of the ORR mechanism that have been established and widely accepted to date. Indeed, such conflict may, at least in some cases, be the result of a "pragmatic approach," targeting system parameterization while knowingly detaching the result from any physical or mechanistic meaning. Unfortunately, it does not take much for such reported apparent parameters to be considered relevant to real interfacial kinetics and to be of mechanistic significance, leaving uncertainty regarding the key reported ORR kinetic parameters and proposed ORR mechanisms.

Once the key role of the overpotential with respect to $E_{\mathrm{Pt}\left(\mathrm{H}_{2} \mathrm{O}\right) / \mathrm{Pt}^{-} \mathrm{OH}_{\text {ads }}}^{0}$ in securing active surface sites has been realized, new light is shed on the $\mathrm{Mn}-\mathrm{O}$ or $\mathrm{M}-\mathrm{OH}$ 
bond energy as a yardstick for the activity of a metal or metal alloy surface in the ORR. Because the generation of active metal sites is likely the important key to achieving practical ORR rates at high, relevant cathode potentials, it can be understood why an optimized $\mathrm{M}-\mathrm{Ox}$ bond strength may indeed become an effective yardstick, almost irrespective of the details of the mechanism of the ORR at an exposed active metal site.

The new analysis of the ORR offered here helps to reconcile experimental findings, particularly those reported recently for ORR at dispersed Pt catalysts in the PEFC cathodes [Neyerlin et al., 2006], and the likely molecular level mechanism of the ORR at Pt metal. The apparent Tafel slope of $60 \mathrm{mV} /$ decade through the fuel-cell-relevant potential domain can be fully explained by an intrinsic "classical" Tafel slope of $120 \mathrm{mV} /$ decade for ORR at Pt metal, modified by the added effect of the cathode overpotential in generating more active metal surface sites (see Fig. 1.6). True, a Tafel slope cannot by itself serve to establish the overall mechanism of a complex process such as the ORR. However, it is certainly important, on the other hand, to examine why the prevalent assignment of the first electron and proton transfer step as rate-determining in the ORR is in apparent conflict with results of measurements on a fuel cell cathode catalyst [Neyerlin et al., 2006]. The elucidation that the value of the intrinsic Tafel slope for the ORR on Pt metal is, in fact, not different than $120 \mathrm{mV} /$ decade at the dispersed fuel cell Pt cathode catalyst [see Equation (1.6) and Fig. 1.6], whereas the apparent smaller reaction order of around 0.5 could be the result of enhanced Pt surface oxidation (i.e., enhanced ORR catalyst deactivation) with increase in oxygen pressure at elevated temperatures [see Equation (1.9b)], restores confidence in the assignment of the Reaction (1.2) as rate-determining in the ORR at a Pt cathode catalyst. The analysis used here also brings home the full impact of the complex dependence of the ORR process on the nature of the actual Pt catalyst surface in the fuel-cell-relevant potential range, this catalyst surface having a composition and structure that vary with potential, temperature, and time, resulting in a behavior that can be explained only when such surface modification effects are considered in the rate expressions.

\section{ACKNOWLEDGMENTS}

Thanks are due to the organizers of the Leiden meeting for a very pleasant and stimulating event.

The idea that the cathode potential with respect to $E_{\mathrm{Pt}\left(\mathrm{H}_{2} \mathrm{O}\right) / \mathrm{Pt}-\mathrm{OH}_{\text {ads }}}^{\mathrm{O}}$ determines the value of the pre-exponential factor in the ORR rate expression was inspired by a comment by Andy Gewirth (Urbana) in his talk in Leiden, pointing to the value of Pourbaix diagrams for understanding ORR electrocatalysis. Indeed, the information on these ORR-mediating and facilitating $\mathrm{M} / \mathrm{M}-\mathrm{OH}$ surface redox systems is to be found in Pourbaix's Atlas.

Extensive discussions with Hubert Gasteiger of the GM Fuel Cell Project (and now with ACTA) and with Jan Rossmeisl of Lyngby, Denmark, are gratefully acknowledged. It would be fair to add that these discussions did not resolve key disagreements; however, they were certainly conducted in and with good spirit. 


\section{REFERENCES}

Anderson AB, Albu TV. 2000. Catalytic effect of platinum on oxygen reduction. An ab initio model including electrode potential dependence. J Electrochem Soc 147: 4229-4238.

Conway BE, Barnett B, Angerstein-Kozlowska H, Tilak BV. 1990. A surface-electrochemical basis for the direct logarithmic growth law for initial stages of extension of anodic oxide films formed at noble metals. J Chem Phys 93: 8361-8373.

Debe MK. 2003. In: Vielstich W, Lamm A, Gasteiger HA, eds. Handbook of Fuel Cells. Volume 3. New York: Wiley, Chapter 45.

Desai SK, Neurock M. 2003. First-principles study of the role of solvent in the dissociation of water over a Pt-Ru alloy. Phys Rev B 68: 075420.

Eickes C, Piela P, Davey J, Zelenay P. 2006. Recoverable cathode performance loss in direct methanol fuel cells. J Electrochem Soc 153: A171-A178.

Gasteiger HA. 2005. In: Proceedings of the International Fuel Cell Workshop, Kofu, Japan; September.

Makharia R, Mathias MF, Baker DR. 2005. Measurement of catalyst layer electrolyte resistance in PEFCs using electrochemical impedance spectroscopy. J Electrochem Soc 152: A970A977.

Mukerjee S, Srinivasan S. 1993. Enhanced electrocatalysis of oxygen reduction on platinum alloys in proton exchange membrane fuel cells. J Electroanal Chem 357: 201-224.

Mukerjee S, Srinivasan S, Soriaga MP, McBreen J. 1995. Role of structural and electronic properties of Pt and Pt alloys on electrocatalysis of oxygen reduction. J Electrochem Soc 142: $1409-1422$.

Neyerlin KC, Gu W, Jorne J, Gasteiger HA. 2006. Determination of catalyst unique parameters for the oxygen reduction reaction in a PEMFC. J Electrochem Soc 153: A1955-A1963.

Nørskov JK, Rossmeisl J, et al. 2004. Origin of the overpotential for oxygen reduction at a fuelcell cathode. J Phys Chem B 108: 17886.

Paik CH, Jarvi TD, O'Grady WE. 2004. Extent of PEMFC cathode surface oxidation by oxygen and water measured by CV. Electrochem Solid State Lett 7: A82-A84.

Panchenko A, Koper MTM, et al. 2004. Ab initio calculations of intermediates of oxygen reduction on low-index platinum surfaces. J Electrochem Soc 151: A2016-A2027.

Parthasarathy A, Srinivasan S, Appleby AJ, et al. 1992a. Temperature dependence of the electrode kinetics of oxygen reduction at the platinum/Nafion ${ }^{\circledR}$ interface-A microelectrode investigation. J Electrochem Soc 139: 2530-2537.

Parthasarathy A, Srinivasan S, Appleby AJ, et al. 1992b. Pressure dependence of the oxygen reduction reaction at the platinum microelectrode/Nafion interface: Electrode kinetics and mass transport. J Electrochem Soc 139: 2856-2862.

Petrow HG, Allen RJ. 1977. US Patent No. 4,044,193; August.

Raistrick ID. 1986. In: Van Zee JW, White RE, Kinoshita K, et al., eds. Diaphragms, Separators and Ion Exchange Membranes. Pennington: The Electrochemical Society Softbound Proceedings Series. PV 86-13. p. 172.

Springer TE, Wilson MS, Gottesfeld S. 1993. Modeling and experimental diagnostics in polymer electrolyte fuel cells. J Electrochem Soc 140: 3513-3526.

Thompset D, 2007. ECS Fall Meeting, Washington, DC.

Toyota R\&D Center 2007. ECS Meeting Report, Washington, DC; October. 
Uribe FA, Wilson MS, Gottesfeld S. 1992. Electrochem Soc Proc 92-11: 494.

Wang JX, Markovic NM, Adzic RR. 2004. Kinetic analysis of oxygen reduction on Pt(111) in acid solutions: Intrinsic kinetic parameters and anion adsorption effects. J Phys Chem B 108: $4127-4133$.

Wang JX, Springer TE, Adzic RR. 2006. Dual-pathway kinetic equation for the hydrogen oxidation reaction on Pt electrodes. J Electrochem Soc 153: A1732-A1740.

Weaver MJ. 2002. Surface-enhanced Raman spectroscopy as a versatile in situ probe of chemisorption in catalytic electrochemical and gaseous environments. J Raman Spectrosc 33: 309.

Wilson MS, Gottesfeld S. 1992. High performance catalyzed membranes of ultra-low Pt loadings for polymer electrolyte fuel cells. J Electrochem Soc 139: L28-L30.

Wilson MS. 1993. US Pat Nos. 5,211,984 and 5,234,777.

Zhang J, Mo Y, Vukmirovic MB, Klie R, Sasaki K, Adzic RR. 2004. Platinum monolayer electrocatalysts for $\mathrm{O}_{2}$ reduction: $\mathrm{Pt}$ monolayer on $\mathrm{Pd}(111)$ and on carbon-supported $\mathrm{Pd}$ nanoparticles. J Phys Chem B 108: 10955-10964. 